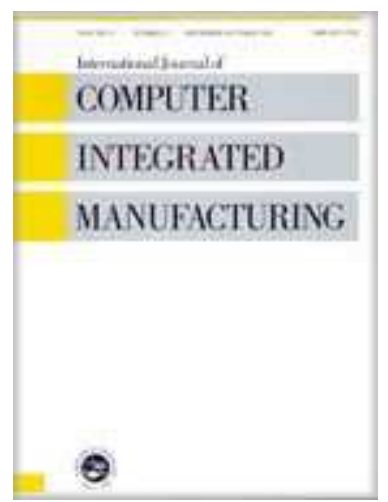

\title{
A Simulated Annealing-based Optimization Approach for Integrated Process Planning and Scheduling
}

\begin{tabular}{|c|c|}
\hline Journal: & International Journal of Computer Integrated Manufacturing \\
\hline Manuscript ID: & TCIM-2005-IJCIM-0057.R2 \\
\hline Manuscript Type: & Original Manuscript \\
\hline $\begin{array}{r}\text { Date Submitted by the } \\
\text { Author: }\end{array}$ & 17-Feb-2006 \\
\hline Complete List of Authors: & $\begin{array}{l}\mathrm{Li}, \text { WD; Mechanical Engineering } \\
\text { McMahon, Chris }\end{array}$ \\
\hline Keywords: & $\begin{array}{l}\text { ADVANCED MANUFACTURING TECHNOLOGY, AI IN } \\
\text { MANUFACTURING SYTEMS, ALGORITHMS }\end{array}$ \\
\hline Keywords (user): & \\
\hline
\end{tabular}

\section{(5) ScholaroNE \\ Manuscript Central}




\title{
A Simulated Annealing-based Optimization Approach for
}

\section{Integrated Process Planning and Scheduling}

\author{
W.D. $\mathrm{Li}^{*}$ and C.A. McMahon \\ Department of Mechanical Engineering, University of Bath \\ Bath, BA2 7AY, U.K. \\ *Tel: +44-(0)1225 386131, Fax: +44-(0)1225 386928, Email: w.li2@bath.ac.uk
}

\begin{abstract}
A job shop needs to deal with a lot of make-to-order business, in which the orders are usually diverse in types but each one is small in volume. To increase the flexibility and responsiveness of the job shop in the more competitive market, process planning and scheduling modules have been actively developed and deployed. The functions of the two modules are usually complementary. It is ideal to integrate them more tightly to achieve the global optimization of product development and manufacturing. In this paper, a unified representation model and a simulated annealing-based approach have been developed to facilitate the integration and optimization process. In the approach, three strategies, including processing flexibility, operation sequencing flexibility and scheduling flexibility, have been used for exploring the search space to support the optimization process effectively. Performance criteria, such as makespan, the balanced level of machine utilization, job tardiness and manufacturing cost, have been systematically defined to make the algorithm adaptive to meet various practical requirements. Case studies under various working conditions and the comparisons of this approach with two modern evolutionary approaches are given. The merits and characteristics of the approach are thereby highlighted.

Keywords: Simulated annealing, process planning, scheduling, integration of process planning and scheduling
\end{abstract}

\section{Introduction}


A job shop manufacturing environment is characterized by the make-to-order operation and the demands of small volumes with a large variety. To support it effectively, computer-aided process planning and scheduling systems have been developed. These systems can free humans from planning and scheduling manufacturing processes/resources for design parts and to optimize decisions during these processes. Based on them, greater automation and intelligence in the product development can be achieved (Chang, 1990; Gu and Norrie, 1995; McMahon and Browne, 1998; Carpenter and Maropoulos, 2000; Case, et al., 2000). Process planning and scheduling are usually complementary activities. The former can be used to plan manufacturing resources and operations for a part to ensure the application of good manufacturing practice and maintain the consistency of the desired functional specifications of the part during its production processes. During the process, it usually assumes that all the applicable manufacturing resources are available for this part. The latter is to handle a group of parts with temporal constraints and competitive manufacturing resources, and decide how and when to assign the manufacturing resources to the parts. In a complex manufacturing situation, it is ideal to integrate the planning and scheduling more closely to achieve a global optimum in manufacturing, and increase the flexibility and responsiveness of the systems.

Traditionally, the integration and interactions of process planning and scheduling are through an iterative and empirical fashion. The process planning system first generates a reasonable process plan for each part. Crucial processes in the system include determining suitable manufacturing resources (machines and tools), selecting set-up plans and sequencing machining operations of the part. The scheduling system then specifies the schedule of manufacturing resources on each operation (job) of the parts according to the importance of jobs, availability of resources and time constraints. It is usually difficult to produce a satisfactory result in a single iteration of the execution of the two systems. For the process planning system, the decision of selecting machines and tools is usually made based on objectives to achieve the minimal manufacturing cost and ensure the good manufacturability of a part. Not all the generated process 
plans for a group of parts are schedulable according to the time and resource feasibility in a job shop. To overcome it, it is necessary to iteratively re-invoke the process planning system to produce alternative plans for further trials until an acceptable scheduling solution is obtained. However, the above iterative process brings forth two serious problems in practical applications. First, it is quite tedious and time-consuming to search for a feasible solution to meet the requirements of process planning and scheduling simultaneously, and an overall optimized target is even more difficult to achieve. Meanwhile, the value of a process plan can be severely discounted since the assumption that all resources are available during the process planning stage might not be fully valid in the scheduling stage. For instance, the generated process plans sometimes cause some machines to be overloaded, further to create bottlenecks and restrict the capabilities of machines. Second, a job shop is usually in a dynamic adjustment due to the nonavailability and maintenance of resources, or the arrival and insertion of new jobs. Such a dynamic shop floor brings challenges for the process planning system to accommodate the changes efficiently, and a new round of searching and compromise of the process planning and scheduling needs to be carried out again in their vast solution spaces.

As a consequence of the above, a closer integration of process planning and scheduling is required. To realize this, a more flexible optimization strategy needs to be adopted to address the various objectives and enable more dynamic interactions and information sharing between the two functions. In this paper, a unified representation model has been developed to incorporate the two functions. Based on this model, a Simulated Annealing (SA)-based approach has been developed to optimize the integration problem. Three strategies - processing flexibility, operation sequencing flexibility and scheduling flexibility, have been proposed to explore the vast search space effectively to support the optimization approach. Performance criteria, such as makespan, the balanced level of machine utilization, job tardiness and manufacturing cost, have been defined in the optimization approach to address the various practical requirements. Through case studies, and the comparisons of this approach with a Genetic Algorithm (GA)-based approach and a 
Particle Swarm Optimization (PSO)-based approach under different working conditions, the merits and characteristics of the approach can be shown clearly.

\section{Recently Related Works}

In the past decade, a number of research works have appeared to address the integration of process planning and scheduling. Some earlier works have been summarized by Tan and Khoshnevis (2000). The most recent works can be generally classified into two categories: the enumerative approach and the simultaneous approach.

In the enumerative approach, all of the possible alternative process plans for each part are first generated. A schedule is then determined by choosing a suitable process plan of each part from their alterative sets according to the current resource constraints of a job shop and scheduling performance criteria (Tonshoff, et al., 1992; Zhang and Mallur, 1994; Zijm, 1995; Sormaz and Khoshnevis, 2003; Kumar and Rajotia, 2003, 2005). Various strategies have been developed to exhaustively identify the possible alternative process plans based on multiple candidate manufacturing processes, set-up plans and manufacturing resources. In the FLEXPLAN system (Tonshoff, et al., 1992), a Petri-net has been used to model and analyze the flexibility of process planning, and an $\mathrm{AND} / \mathrm{OR}$ graph has been developed to represent the generated alternative plans. Based on the process plans, a strategy to pursue the minimum process time has been used to select the most suitable plan for each part from the scheduling point of view. The IPPM (Integrated Process Plan Model) system is another example with this approach (Zhang and Mallur, 1994). A decision matrix has been first developed to represent and store all of the possible process plans generated using different set-ups and machine tools. In the matrix, the fuzzy logic technique has been incorporated to represent the imprecise information in the selection of the set-ups and machine tools. A scheduler then chooses a suitable process plan based on the shortest processing time principle. Sormaz and Khoshnevis (2003) summarized the general procedure to generate alternative process plans for a part as four steps: selecting manufacturing 
processes and operations for features, specifying machines and tools, estimating time and cost, and generating a process plan network. In the first two steps, features are associated with manufacturing processes, machines and tools based on established knowledge bases. In the third step, a criterion is defined to evaluate alternative process plans in terms of the set-up cost, the machining operation cost, the machine change cost, the tool change cost and the manufacturing time. In the fourth step, a hierarchical structure is used to represent and store the alternative plans. However, the common drawback of the above research works is that it is quite time-consuming to randomly identify all possible alternative process plans for complex parts. On the other hand, through a number of experimental computations, Usher (2003) concluded that the advantage gained by increasing the number of alternative process plans for a scheduling system to choose from diminishes rapidly when the number of the plans reaches a certain level.

The simultaneous approach is more effective and efficient to integrate the two functions. In this approach, the process planning and scheduling are both in dynamic adjustment until satisfactory performance criteria can be reached. To facilitate the process, intelligent evolutionary algorithms, such as GA, SA, and heuristic rules, have recently been employed to generate optimized plans satisfying the constraints and objectives of process planning and scheduling simultaneously. In some works, two-level hierarchical structures have been proposed to model the integration problem. Satisfactory schedules are determined in a high level of the structure based on the dynamic adjustments of some cost-effective process plans generated and maintained in a low level of the structure (Brandimarte, et al., 1995; Zhang, et al., 2003). In Brandimarte et al.'s work (1995), both the process planning and scheduling are represented in linear mixed integer programming. The process planning module can produce good process plans with low operation costs. If a schedule generated based on the process plans is not satisfied in makespan, a heuristic procedure is invoked to reallocate some critical operations to alternative machines. In Zhang et al.'s work (2003), for each part, a process planning module based on a GA or a SA identifies optimal or near-optimal process plans with the minimum manufacturing cost. A scheduling 
module takes the optimal or near-optimal plans of each part and generates a schedule based on a given criterion, such as the balanced machine utilization or the lowest number of tardy jobs. A facilitator between the two modules coordinates their communications and interactions. Usually an initial schedule is not satisfied, and it needs to be fed back to the facilitator to identify a particular job (part) for further adjustment. A change is made for the part to generate other costeffective alternative process plans to enhance the scheduling performance. The above two approaches are improved from the traditional iterative integration approach in a way that the scheduling module can guide the searching direction for the most suitable process plans from both the process planning and scheduling perspectives. To further enhance the algorithm performance, some unified optimization models and algorithms have been developed (Morad and Zalzala, 1999; Kim, et al., 2003; Yan, et al., 2003; Zhang and Yan, 2005). Morad and Zalzala (1999) developed a GA-based integration scheme, in which process plans have been represented as chromosomes, and crossover and mutations operations have been used to explore the alternative process plans. The performance criterion to choose a satisfactory schedule from the process plans can be the minimum makespan, the set-up cost, or the tardiness. Kim, et al. (2003) developed a single optimization model to integrate the process planning and scheduling. In the work, three rules, which are operation flexibility, sequencing flexibility and processing flexibility, have been employed to generate multiple process plans. From these multiple plans, a symbiotic GA has been used to search for an optimized process plan that satisfies scheduling objectives, such as the minimum makespan or the mean flow time. Yan, et al. (2003) and Zhang and Yan (2005) developed an optimization model to combine the considerations from process planning and scheduling, such as the production cost, the tardiness time, the set-up cost, and the early finish time. Based on it, a Tabu Search (TS)-based approach (Yan, et al., 2003) and an improved hybrid GA-based approach (Zhang and Yan, 2005) have been designed to optimize planning and scheduling simultaneously. However, the following two issues are still outstanding and require careful considerations in future work. 
First, in the process planning and scheduling, different criteria are used to address specific practical cases. For instance, from the process planning perspective, the lowest manufacturing cost is usually a desired target, while the scheduling usually needs to look for the most balanced utilization of machines, the minimum number of tardy jobs, the shortest makespan, etc. To meet the various requirements in practical situations, further improvement is required on the optimization algorithm to make it more adaptive to accommodate diverse objectives for users to choose from.

Second, both process planning and scheduling are $N P$-hard combinatorial optimization problems. Complex manufacturing constraints, such as operation precedence constraints and manufacturing resource constraints, need to be considered as well. The simultaneous integration scheme generates an intractable optimization problem with a vast exploration space. Therefore, the optimization algorithm needs to be more agile and efficient by adopting intelligent heuristic and searching strategies.

\section{Integrated Process Planning and Scheduling}

\subsection{Representations for process plans and schedules}

Process planning and scheduling are both essential functional modules in product development and manufacturing. The major considerations in process planning include: (1) generating machining operations based on the features of a part to meet desired functional specifications and achieve good manufacturability, (2) identifying machining resources applicable to the operations, and (3) determining the set-up plan and operation sequence according to some cost-effective criteria. Therefore, a process plan for a part can be represented by a series of machining operations, applicable resources for the operations, set-up plans, operation sequence, etc. A set-up can be generally defined as a group of operations that are manufactured on a single machine with the same fixture. Here, a set-up is specified as a group of features with the same 
Tool Approaching Direction (TAD) machined on a machine. For instance, in Fig. 1, a hole with two TADs is considered to be related to two alternative set-ups (Li, et al., 2002).

(Here insert Fig. 1)

Based on the generated process plans of parts, the scheduling task is to assign the parts and their machining operations to specific machines to be executed in different time slots, targeting at a good shop floor performance, such as the shortest makespan, the most balanced machine utilization, the least total tardiness, etc.

Usually, a part can be manufactured through different process plans. A group of alternative process plans can be generated using two strategies: processing flexibility and operation sequencing flexibility. Processing flexibility refers to the possibility of performing an operation on alternative machines with alternative TADs or tools. Operation sequencing flexibility corresponds to the possibility of interchanging the sequence in which the operations are performed. For a group of parts, alternative schedules can be created based on scheduling flexibility, which relates to the possibility of arranging different schedules to manufacture the parts and the operations. For a shop floor with multiple available manufacturing resources, a group of parts can generate a vast search space for determining process plans and schedules. To facilitate the searching and optimization process, an intelligent algorithm is imperative to look for desired optimized results effectively according to process planning and scheduling criteria. In Fig. 2 , the three strategies to generate alternative process plans or schedules, i.e., processing flexibility, operation sequencing flexibility and scheduling flexibility, are illustrated. For the processing flexibility strategy shown in (a), an alternative process plan of a part can be generated if the different group of machine, tool and TAD is chosen. With applying the operation sequencing strategy shown in (b), different sequences of operations can be arranged in a part to produce alternative process plans as well. The above two strategies are used to generate alternative plans whereas the scheduling flexibility strategy, which is illustrated in (c), can choose a new arrangement of the part sequence so as to bring about a new scheduling. 
(Here insert Fig. 2)

To apply an intelligent algorithm to the optimization of process planning and scheduling, two sets of data structures are defined here. The first set is process planning-oriented to represent the process plans of a part, and the second set is scheduling-oriented to specify the schedule of a group of parts. Each operation of a process plan for a part can be represented in a class Operation. Based on this class, a process plan can be represented in a class Process_Plan. The details of these two classes are given in Fig. 3 and Table 1. The Process_Plan class consists of a series of operations. It assumes that a process plan of a part has $n$ operations for machining the part, and its sequence is the operation sequence of the process plan. The Operation class consists of three types of data: the indices for the operation and the part that the operation belongs to, the applicable (machines, tools and TADs) for the operation, and the chosen (machine, tool and TAD) to execute the operation. In the Process_Plan, the manufacturing cost for the process plan of a part has been defined in ( $\mathrm{Li}$, et al., 2002, 2004) to include the costs from the machine utilization, the tool utilization, the set-ups, the machine changes and the tool changes. The connection of these two sets is maintained through the operations of the parts, which is shown in Fig. 4.

(Here insert Fig. 3, Fig. 4 and Table 1)

A Gantt chart has been popularly used to represent a schedule of a group of parts (McMahon and Browne, 1998). In the Gantt chart, the order in which the parts and their operations are carried out is laid out and the dependencies of the tasks are managed. The X axis of the Gantt chart represents time. Each row in the $\mathrm{Y}$ axis represents a machine and the specific arrangement for the operations of the parts on the machine. Each machine is represented as a class Machine, which is defined in Fig. 5 and Table 2. The Machine class is comprised of a number of time slots, which can be further classified into idle time slots, preparation time slots for machining operations (further including the set-up time, the machine change time, or the tool change time), and machining time slots of operations. In the class, the starting and ending moments for each 
operation are indicated to facilitate some performance computations. The items and the relevant computations in Tables 1 and 2 are given in the following Section 3.2.

(Here insert Fig. 5 and Table 2)

\subsection{Performance criteria}

Some essential criteria based on time to evaluate the performances of process plans and schedules are defined here, which include the manufacturing cost, the makespan, the job tardiness, and the balanced level of the machine utilization. Meanwhile, a set of functions to support the relevant calculations is also defined. In the formulas, there are two assumptions. The first assumption is that there are $m$ machines available in a job shop. The second assumption is that there are $n$ operations to be executed on it for a specific machine. Operation $i$ is denoted as Operation[i] . Machine $j$ is denoted as Machine $[j] . \quad \Omega_{1}(X, Y)=\left\{\begin{array}{ll}1 & X \neq Y \\ 0 & X=Y\end{array}\right.$, and $\Omega_{2}(X, Y)=\left\{\begin{array}{ll}0 & X=Y=0 \\ 1 & \text { otherwise }\end{array}\right.$.

(1) Set-up Time for Operation[i] - Operation[i].Setup_T:

For the first operation in a machine, there is a set-up ( Setup ). For two consecutive operations, a set-up is defined in Table 3, and it computation is below (the first operation needs a set-up):

$$
\begin{aligned}
& \text { Operation[1].Setup }=1 \text {, and } \\
& \text { Operation[i].Setup }=\Omega_{2}\left(\Omega_{1}(\text { Operation[i].Part_id,OPeration[i-1].Part_id })\right. \text {, } \\
& \left.\Omega_{1}(\text { Operation[i].Setup_id,OPeration[i-1].Setup_id })\right),(i=2, \ldots n)
\end{aligned}
$$

\section{(Equation 1)}

That is, a set-up is required for the first operation. The number of set-ups required for other operations will be determined by the Part_id and Setup_id of an operation and the operation just prior to it. 
The set-up time for each set-up is considered to be the same, and Setup _Index is the time index for each set-up. Hence,

$$
\text { Operation[i].Setup_T }=\text { Operation[i].Setup } * \text { Setup_Index },(i=1, \ldots n)
$$

(Here insert Table 3)

(2) Machine Change Time for Operation[i] - Operation[i].MC_ $T$ :

A machine change of Operation $[i]$ is denoted as Operation $[i] . M C$, and it relevant computation is below (the change for the first operation is 1 ):

$$
\begin{aligned}
& \text { Operation[1].MC }=1 \text {, and } \\
& \text { Operation }[i] \cdot M C=\Omega_{1}(\text { Operation }[i] \cdot \text { Part_id }, \text { Operation }[i-1] \cdot \text { Part_id }),(i=2, \ldots n)
\end{aligned}
$$

\section{(Equation 3)}

That is, a machine change is required for the first operation. The number of machine changes required for other operations will be determined by the Part_id of an operation and the operation just prior to it.

The machine change time is considered to be the same for each machine change, and $M C_{-}$Index is the time index for each machine change. Hence,

$$
\text { Operation }[i] \cdot M C_{-} T=\text { Operation }[i] \cdot M C^{*} M C_{-} \text {Index },(i=1, \ldots n)
$$

\section{(3) Tool Change Time for Operation[i] - Operation $[i] \cdot T C_{-} T$ :}

A tool change of Operation $[i]$ is denoted as Operation[i].TC, and the relevant computation is below (the change for the first operation is 1 ).

Operation $[1] . T C=1$, and

Operation $[i] \cdot T C=\Omega_{1}\left(\right.$ Operation$[i] . T o o l_{-} i d$, Operation $\left.[i-1] . T o o l \_i d\right),(i=2, \ldots n)$

(Equation 5) 
That is, a tool change is required for the first operation. The number of tool changes required for other operations will be determined by the Tool_id of an operation and the operation just prior to it.

The tool change time is considered to be the same for each machine change, and TC_Index is the time index for each tool change. Hence,

$$
\text { Operation }[i] \cdot T C_{-} T=\text { Operation }[i] \cdot T C * T C_{-} \text {Index },(i=1, \ldots n)
$$

(4) Preparation Time for Operation $[i]-$ Operation $[i] . \operatorname{Pr} e_{-} T$ :

The preparation time for an operation consists of the setup time, the machine change time and the tool change time for the operation. That is:

Operation $[i] . \operatorname{Pr} e_{-} T=$ Operation $[i]$ Setup $\_T+$ Operation $[i] \cdot M C_{-} T+$ Operation $[i] \cdot T C_{-} T,(i=1, \ldots n)$

\section{(Equation 7)}

(5) Idle time for Operation[i] - Operation[i].Idle _ $T$ :

Operation[1].Idle _ $T$ is the start time of the machine to execute Operation[1], and

$$
\begin{aligned}
& \text { Operation[i].Idle _ } T=\text { Operation[i].Start_ } M-\text { Operation[ }[i-1] . \text { Start }_{-} M- \\
& \text { Operation }[i-1] . \operatorname{Pr} e_{-} T-\text { Operation }[i-1] . M a c_{-} T \quad,(i=2, \ldots n)
\end{aligned}
$$

\section{(Equation 8)}

where Operation[i].Start_M is the start time for Operation[i], and Operation[i].Mac $\_T$ is the machining time for Operation $[i]$.

(6) Total Time for Machine $[j]-$ Machine $[j]$. Total $_{-} T$ :

The total occupation time starts with its start utilization moment, and the calculation consists of the idle time, preparation time and machining time of all operations. That is: 


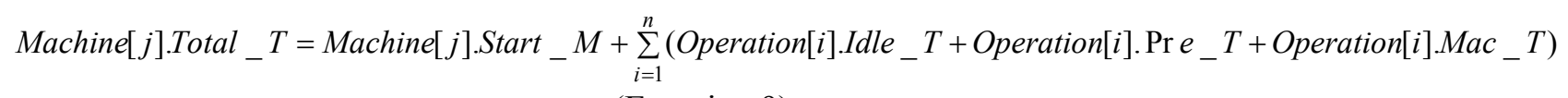
(Equation 9)

(7) Makespan:

$$
\text { Makespan }=\underset{j=1}{m}\left(\text { Machine }[j] . \text { Total } \_T\right)
$$

(8) Balanced level of machine utilization:

The Standard Deviation concept is introduced here to evaluate the balanced machine utilization (assuming there are $m$ machines, and each machine has $n$ operations).

$$
\begin{aligned}
& \text { Average_Utilization }=\frac{\sum_{i=1}^{n}\left(\text { Operation }[i] \cdot M a c_{-} T\right)}{n},(j=1, . ., m) \\
& \chi=\frac{\sum_{j=1}^{m}(\text { Machine }[j] \cdot \text { Utilization })}{m} \\
& \text { Utilization_Level }=\sqrt{\sum_{j=1}^{m}(\text { Machine }[j] \cdot \text {.Utilization }-\chi)^{2}}
\end{aligned}
$$

(9) Part tardiness:

The due date of a part is denoted as $D D$, and the completion moment of the part is denoted as $C M$. Hence,

$$
\text { Part_Tardiness }=\left\{\begin{array}{cl}
0 & \text { if DD is later than } C M \\
C M-D D & \text { Otherwise }
\end{array}\right.
$$

(10) Manufacturing cost for the process plan of a part: 
In Li, et al.'s previous work, the manufacturing cost associated with the process plan of a part has been defined in terms of machine utilization, tool utilization, set-up changes, machine changes and tool changes. The relevant computations are elaborated in (Li, et al., 2002, 2004).

Manufacturing constraints and a constraint-handling algorithm for the operations in a process plan have been developed to ensure the manufacturability of the generated process plans. The definitions of the constraints and the constraint-handling algorithm can be found in ( $\mathrm{Li}$, et al., 2002, 2004).

\section{Simulated Annealing-based Optimization Approach}

A SA is a stochastic searching algorithm, and it comes from an algorithmic analogy with the annealing of materials where the purpose is to lead the material to a state corresponding to a global minimum of its internal energy. One of the major advantages of a SA is that it enables the finding of the global minimum of an objective function in a complex search space efficiently. In SA, a parameter called "temperature" is used to guide and control the iterations of the algorithm (Kirkpatrick, et al., 1983). The temperature begins at a high level and is cooled until an equilibrium is reached. The way in which the algorithm avoids being trapped in a local minimum is that it generates and accepts random solutions in which the performance evaluation function has a greater value, i.e., the solution has a higher energy. When the temperature is high, the algorithm will be likely to accept a higher energy solution, while at a very low temperature the algorithm will almost only accept solutions of lower energy (therefore, a finally refined process). Solutions are accepted according to the Boltzman probability (Aarts and Korst, 1989) (the definition is in the following Equation 15).

The structural design of the optimization algorithm is affected by the chosen performance criteria. To be more flexible to meet the various requirements in practical situations, different performance criteria are considered in the algorithm, including (1) manufacturing cost, (2) 
makespan, (3) the balanced level of machine utilization, and (4) part tardiness. It is almost impossible to achieve all of the objectives at the same time since they conflict in many cases. In this algorithm, there are two options embedded to enhance the adaptability:

Option 1: A single criterion is chosen for the optimization algorithm. Based on the feasible process plan for each part, the shortest makespan, the most balanced level of machine utilization, the minimum part tardiness, or the most economic manufacturing cost, is used to guide the searching process.

Option 2: Two or more criteria are incorporated as a simultaneous consideration. The criteria are added up with weights as a single criterion.

The major processes of the SA are described as follows:

(1) Decide "an initial schedule". The schedule is based on the process plan for each part. The process plans are generated by a process planning algorithm (Li, et al., 2002, 2004). A constraint-handling algorithm ( $\mathrm{Li}$, et al., 2002, 2004) is applied to the generated plans to adjust them to satisfy the manufacturing constraints.

(2) The initial schedule is chosen as "the current schedule $S$ ".

(3) Determine the start and end temperatures $T_{0}$ and $T_{1}$. Set "the current temperature $T$ " as $T=T_{0}$.

(4) While not yet frozen $\left(T>T_{1}\right)$, perform Steps (a) - (c):

(a) Generate "a temporary schedule $S$ '” by making some random changes on the current schedule $S$ using several neighbourhood strategies. The neighbourhood strategies are:

- Shift. This strategy removes an operation from its present position and inserts it at another position in the current schedule.

- Adjacent swapping. This strategy exchanges two adjacent operations in the current schedule. 
- Mutation. Two types of mutation strategies are applied. The first mutation strategy exchanges two operations chosen randomly in the current schedule. The second mutation strategy randomly selects an operation in the current schedule, and replaces the set of machine, tool, and the TAD used in this operation from the candidate lists.

After the neighbourhood strategies have been applied, the constraint handling algorithm is applied to $S^{\prime}$ to adjust it to the feasible domain.

(b) Set $\Delta=$ Performance_Criterion $\left(S^{\prime}\right)-$ Performance_Criterion $(S)$. The Performance Criterion function is one of the above defined - makespan, the balanced machine utilization, the part tardiness, the manufacturing cost, or a combined consideration.

If $\Delta \leq 0$ (downhill move):

Set $S=S^{\prime}$.

Else (uphill move):

Choose a random number $r$ from $[0,1]$. Set $S=S^{\prime}$ when $r<e^{-k^{*} \Delta / T}$

(Equation 15)

(c) Return to step (4) after lowering the temperature $T$ as

$T=\alpha^{*} T$

(Equation 16)

where $0<\alpha<1$.

(5) If frozen $\left(T \leq T_{1}\right)$, the algorithm ends.

The value of the parameter $k$ in Equation (15) is determined in the case studies discussed later. To achieve optimal or near-optimal solutions, the cooling process needs to be very slow, and $\alpha$ in Equation (16) should be very close to 1.

\section{Case Studies and Discussions}


The resources of a specific job shop are defined in Table 4. Some assumptions that are commonly used in most of the previous research works regarding scheduling are taken for this study. The assumptions include:

- Parts are independent, and part preemption is not allowed.

- The sequence of the operations of each part complies with manufacturing constraints.

- All parts, machines and tools are available at time zero simultaneously.

- Each operation is performed on a single machine, and each machine can only execute an operation at a time.

- The time for a set-up (represented as a Setup_Index in Section 3.2) is identical and independent of specific operations. The time for a machine change (represented as $M C_{-}$Index) or a tool change (represented as $T C_{-}$Index) follows the same assumption.

- Machines are continuously available for production.

- If a machine or a tool is broken down, or a new part is inserted, the algorithm can restart and generate new process plans and a schedule due to the efficient optimization performance of the algorithm.

(Here insert Table 4)

Based on multiple groups of parts, various experiments have been conducted for different conditions and based on different performance criteria to measure the adaptability and robustness of this approach. Meanwhile, the algorithm has been compared with other popular heuristic or evolutionary algorithms, including GA, TS and PSO for the purposes of benchmarking. The performance of the algorithm is satisfactory from the results of the experiments and comparisons. Here, in order to save space, two groups of parts and some optimization conditions are chosen for illustration.

\section{Group 1:}


The first group consists of three parts (shown in Fig. 6), which are taken from the works of Shah, et al. (1995) and Zhang, et al. (1997). The relevant technical specifications of the three parts are defined in Tables 5, 6 and 7.

(Here insert Fig. 6, Tables 5, 6 and 7)

For this group of parts, the results of the following three conditions are taken here to demonstrate the performance of the algorithm.

1) The performance criterion is makespan (to achieve the minimum makespan).

2) The performance criterion is manufacturing cost (to achieve the minimum cost).

3) The performance criteria are makespan and the balanced utilization of $M_{1}-M_{5}$. The two criteria are incorporated as a single criterion so as to optimize them simultaneously. The criterion is:

$$
\text { Performance_Criterion }=\text { Makespan }+ \text { Weight } * \text { Utilization_Level }
$$

where Weight is used to adjust the incorporation rate of the two criteria to achieve the best performance.

The optimization intermediate results under the above Conditions (1), (2) and (3) are shown in Fig. 7, Fig. 8 and Fig. 9 respectively. All of the results are prone to stabilization after several hundreds of iterations.

(Here insert Fig. 7, 8 and 9)

Fig. 10 and Fig. 11 are used to further indicate the characteristics of the algorithm. In Fig. 10, the manufacturing cost and the makespan are obtained under Condition (2) (in order to put them together for comparison, the manufacturing cost has been magnified 100 times). They follow the similar trends since the reduced numbers of set-ups, machine changes, and tool changes, which are the major optimization targets for Condition (2), contribute to both of the lower manufacturing cost and the shorter makespan. In Fig. 11, the manufacturing cost and the balanced 
utilization of machines are obtained under Condition (2) (the manufacturing cost scale has also been magnified 100 times). A lower manufacturing cost for manufacturing a part can be achieved through the intensive utilization of cheap machines, but it is conflicted with the criterion for the balanced utilization of machines. Therefore, the targets for the lower manufacturing cost and the more balanced utilization of machines are in contradiction, which is clearly reflected in Fig. 11.

(Here insert Fig. 10 and Fig. 11)

\section{Group 2:}

Eight parts taken from (Zhang, et al., 2003) have been used to test the algorithm further. The relevant specifications of the parts are given in Table 8 . The above three conditions have been used again, and the optimization results are shown in Fig. 12, Fig. 13 and Fig. 14. It can be observed that the results for this group of parts follow the similar trends for the parts in Group 1. Through further trials on other groups of parts, the algorithm has been verified to have the stable performance and good optimization results.

(Here insert Table 8, Fig. 12, 13 and 14)

The algorithm has been further compared with two modern evolutionary algorithm-based approaches in terms of optimum results, computation efficiency and robustness. The two algorithms are GA (Genetic Algorithm) and PSO (Particle Swarm Optimization). A GA is modelled based on natural evolution in that the employed operators are inspired by a natural evolution process. These genetic operators, including selection, crossover and mutation, can be used to manipulate the chromosomes (solutions to a problem) in a population over several generations to improve its fitness function gradually (Pham and Karaboga, 2000). A PSO is a recently developed evolutionary algorithm, and it is inspired by the social behaviour of birds flocking or fish schooling (Kennedy and Eberhart, 1995). In a PSO, the potential solutions, called particles, fly through the problem space to find the best solution. The optimization process is controlled by several parameters/functions, such as the fitness function, neighbourhood functions 
and velocity. From the results in Fig. 15 (the results are from Condition (1) of Group 2 for illustration), it can be observed that all of the approaches can reach good results, while different characteristics are shown due to the inherent mechanisms of the algorithms. The SA-based approach usually takes shorter time to find good solutions but it is vigilant to its parameters (such as the starting temperature and the cooling parameter) and the problems to be optimized. The GAand PSO-based approaches are slow in finding good solutions but they are robust for optimization problems. Meanwhile, the SA-based approach is much "sharper" to find optimal or near-optimal solutions, and the common shortcoming of the GA- and PSO-based approaches is that they are prone to pre-maturity in some cases (converge too early and difficult to find the optimal or nearoptimal solutions).

\section{(Here insert Fig. 15)}

\section{Conclusions}

Computer-aided process planning and scheduling systems can effectively automate and optimize decisions in planning and scheduling manufacturing processes/resources for products. Presently, an active research direction is to integrate them more seamlessly to reinforce the whole performance by utilizing their complementary roles in product development and manufacturing. The crucial challenges include how to develop a more effective and intelligent algorithm to identify good solutions in the vast search space of the integrated problem, and how to address different performance objectives to meet various practical requirements.

In this paper, a representation model to unify the process planning and scheduling problems has been designed. Based on this, a SA-based approach has been developed to determine the optimized results from the complex search space effectively and efficiently. Three strategies, i.e., processing flexibility, operation sequencing flexibility and scheduling flexibility, have been used

to support the algorithm to explore the search space extensively. Several commonly used performance criteria in practice, including makespan, the balanced level of machine utilization, 
job tardiness and manufacturing cost, have been developed in the algorithm to meet the various practical requirements. Case studies under various working conditions have been used to test the algorithm, and the comparisons have been made for this approach and two modern evolutionary approaches to indicate their characteristics and advantages. The major contributions of the paper include:

- Based on a unified model to incorporate the process planning and scheduling problems, a set of systematic performance criteria have been developed and embedded in the algorithm. The algorithm is enabled to choose one or more specific criteria to address the different practical requirements, and its adaptability is therefore enhanced.

- Processing flexibility, operation sequencing flexibility and scheduling flexibility can represent the extensive search space effectively. Meanwhile, these strategies can be naturally utilized in various heuristic or evolutionary algorithms to support their operators, such as the crossover, mutation, shifting and swapping of operations, etc. Due to the feature, new heuristic or evolutionary algorithms can be conveniently developed in future based on the algorithm and strategies adopted in the paper.

- The comparisons made for this approach with the other modern optimization algorithms for various case studies and working conditions can indicate the characteristics of the algorithms clearly. The comparisons and analysis can be regarded as a good reference for users to choose the suitable algorithm to meet their specific requirements.

\section{Acknowledgement}

The research reported in this paper has been undertaken at the Engineering Innovative Manufacturing Research Centre (E-IMRC) at the University of Bath, funded by the UK Engineering and Physical Sciences Research Council (EPSRC) under grant GR/R67507/01.

\section{References}


Aarts, E. and Korst, J., 1989, Simulated Annealing and Boltzman Machine, John Wiley \& Sons.

Brandimarte, P. and Calderini, M., 1995, A hierarchical bicriterion approach to integrated process plan selection and job shop scheduling. International Journal of Production Research, 33(1), pp. 161-181.

Carpenter, I.D. and Maropoulos, P.G., 2000, A flexible tool selection decision support system for milling operations. Journal of Materials Processing Technology, 107, pp. 143-152.

Case, K. and Wan Harun, W.A., 2000, Feature-based representation for manufacturing planning. International Journal of Product Research, 38(17), pp. 4285-4300.

Chang, T.C., 1990, Expert Process Planning for Manufacturing, Addison-Wesley, New York, USA.

Gu, P.H. and Norrie, 1995, Intelligent Manufacturing Planning, Kluwer Academic Publishers.

Kennedy, J. and Eberhart, R.C., 1995, Particle swarm optimization. IEEE Proceedings of the International Conference on Neural Networks IV, Perth, Australia (Piscataway: IEEE Service Centre), pp. 1942-1948.

Kim, Y.K., Park, K. and Ko, J., 2003, A symbiotic evolutionary algorithm for the integration of process planning and job shop scheduling. Computers \& Operations Research, 30, pp. 11511171.

Kirkpatrick, S., Gelatt, Jr C.D. and Vecchi M.P., 1983, Optimization by simulated annealing, Science, 220, pp. 671-680.

Kumar, M. and Rajotia, S., 2003, Integration of scheduling with computer aided process planning. Journal of Materials Processing Technology, 138, pp. 297-300.

Kumar, M. and Rajotia, S., 2005, Integration of process planning and scheduling in a job shop environment. International Journal of Advanced Manufacturing Technology, in press.

Li, W.D., Ong, S.K. and Nee, A.Y.C., 2002, A hybrid genetic algorithm and simulated annealing approach for the optimization of process plan for prismatic parts. International Journal of Production Research, 40(8), pp.1899-1922. 
Li, W.D., Ong, S.K. and Nee, A.Y.C., 2004, Optimization of process planning using a constraintbased tabu search method. International Journal of Production Research, 42(10), pp. 19551985.

McMahon, C.A. and Browne, J., 1998, CAD/CAM - Principles, Practice and Manufacturing Management (2rd Edition), Addison-Wesley.

Morad, N. and Zalzala, A., 1999, Genetic algorithms in integrated process planning and scheduling. Journal of Intelligent Manufacturing, 10, pp. 169-179.

Pham, D.T. and Karaboga, D., 2000, Intelligent Optimization Techniques: Genetic Algorithms, Tabu Search, Simulated Annealing and Neural Networks, Springer, London, UK.

Shafaei, R. and Brunn, P., 2000, Workshop scheduling using practical (inaccurate) data. Part 3: a framework to integrate job releasing, routing and scheduling functions to create a robust predictive schedule. International Journal of Production Research, 38(1), pp. 85-99.

Sormaz, D. and Khoshnevis, B., Generation of alternative process plans in integrated manufacturing systems. Journal of Intelligent Manufacturing, 14, pp. 509-526.

Tan, W. and Khoshnevis, B., 2000, Integration of process planning and scheduling - a review. Journal of Intelligent Manufacturing, 11, pp. 51-63.

Tonshoff, H.K., Beckendorff, U. and Andres, N., 1989, FLEXPLAN: A concept for intelligent process planning and scheduling. Proceedings of the CIRP International Workshop, Hannover, Germany, pp. 319-322.

Usher, J.M., 2003, Evaluating the impact of alternative plans on manufacturing performance. Computers \& Industrial Engineering, 45, pp. 585-596.

Yan, H.S., Xia, Q.F., Zhu, M.R. Liu, X.L. and Guo, Z.M., 2003, Integrated production planning and scheduling on automobile assembly lines. IIE Transactions, 35, pp. 711-725.

Zhang, H. and Mallur, S., 1994, An integrated model of process planning and production scheduling. International Journal of Computer Integrated Manufacturing, 7(6), pp. 356-364. 
Zhang, X.D. and Yan, H.S., 2005, Integrated optimization of production planning and scheduling for a kind of job-shop. International Journal of Advanced Manufacturing Technology, in press.

Zhang, Y.F., Saravanan, A.N. and Fuh, J.Y.H., 2003, Integration of process planning and scheduling by exploring the flexibility of process planning. International Journal of Production Research, 41(3), pp. 611-628.

Zijm, W.H.M., 1995, The integration of process planning and shop floor scheduling in small batch part manufacturing. Annals of CIRP, 44, pp. 429-432. 


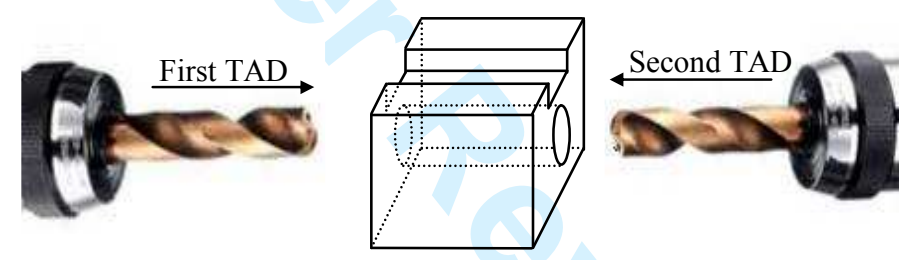

Fig. 1 A through hole with two TADs. 


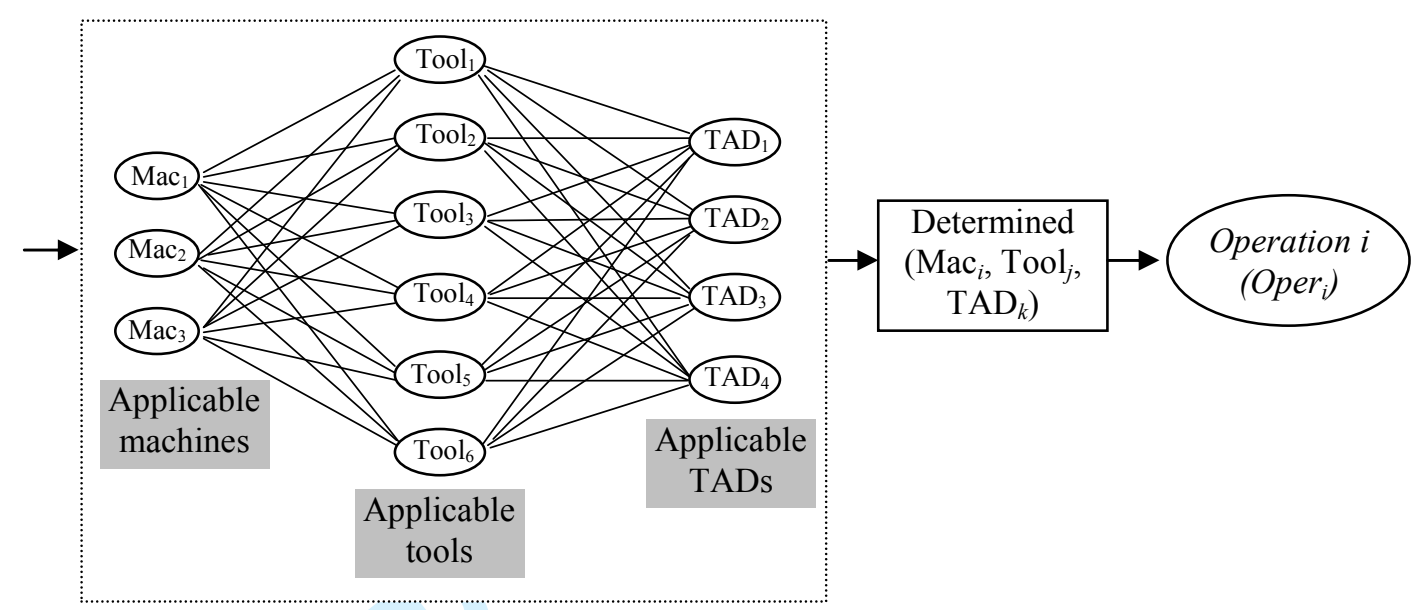

(a) The processing flexibility to generate alternative process plans.

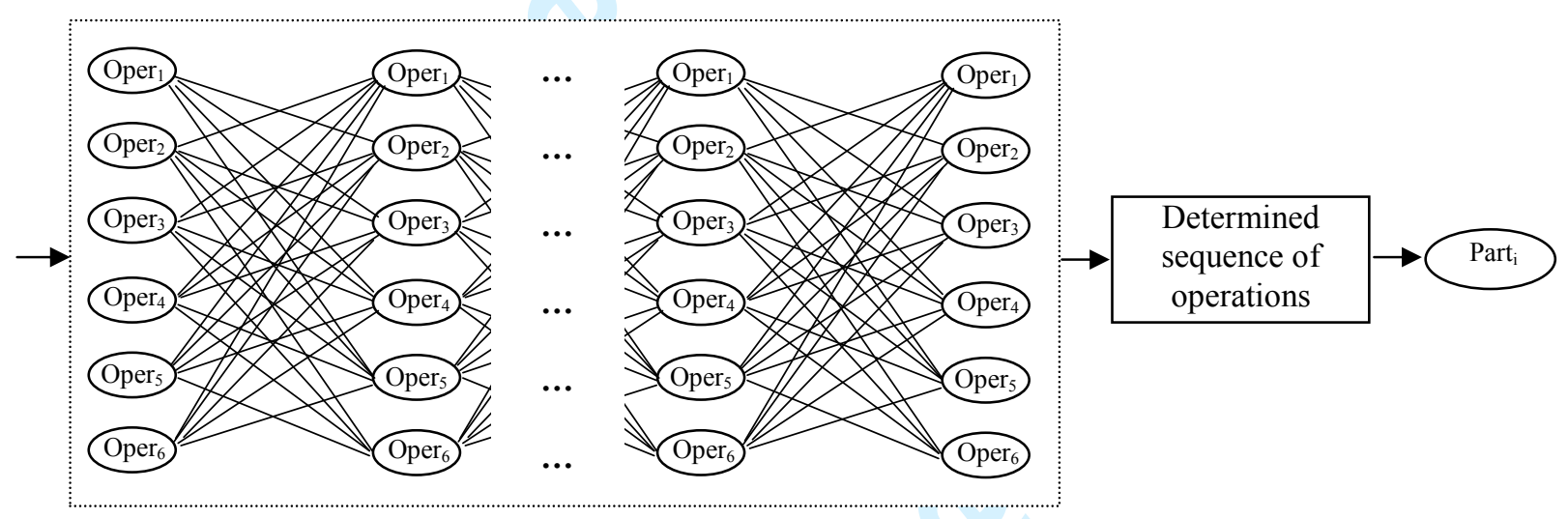

(b) The operation sequencing flexibility to generate alternative process plans.

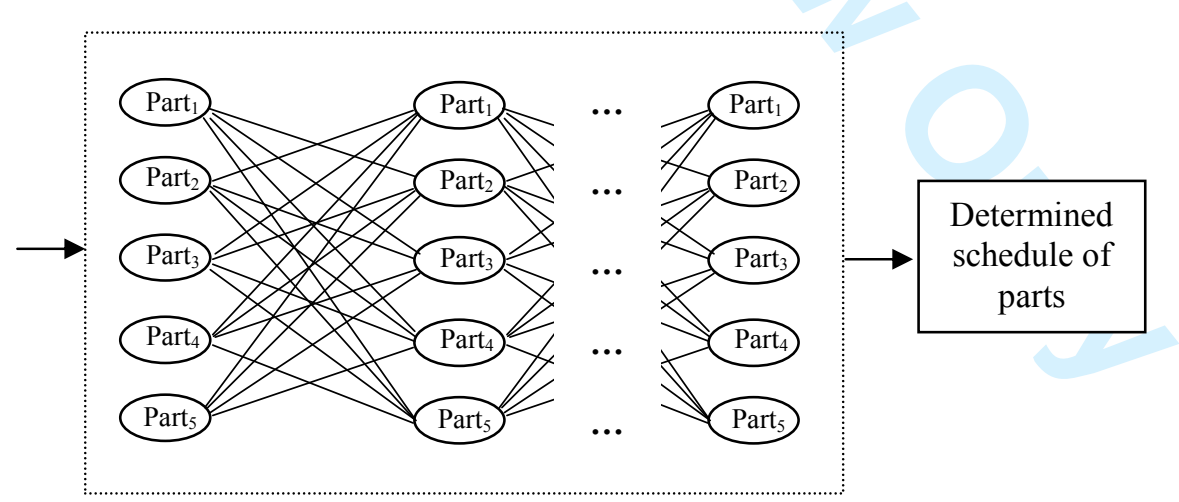

(c) The scheduling flexibility to generate alternative schedules.

Fig. 2 Three strategies to generate alternative process plans or schedules. 


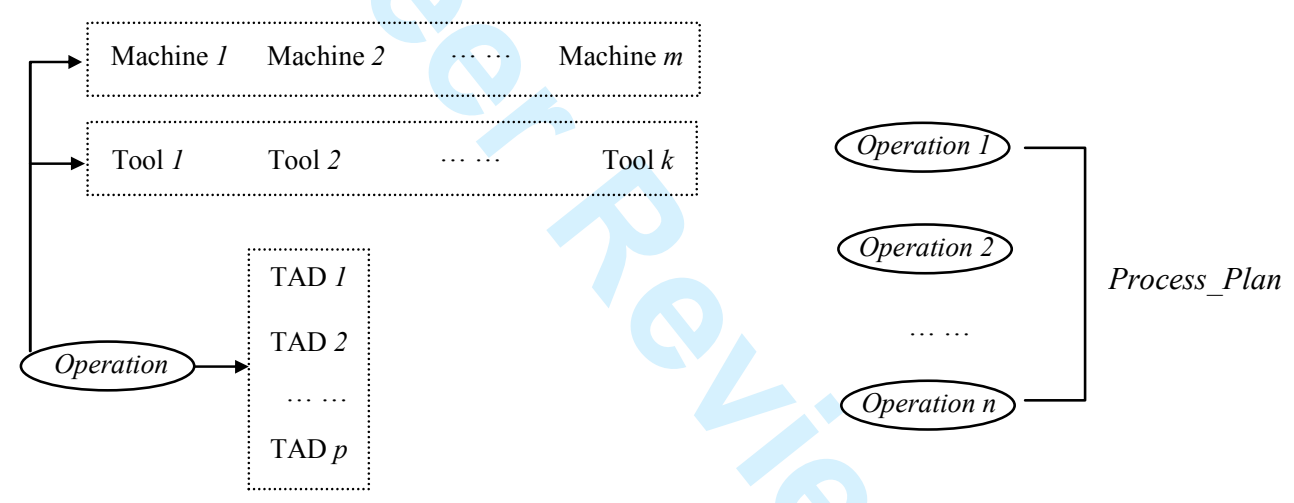

Fig. 3 The illustrations of the classes Operation and Process_Plan. 


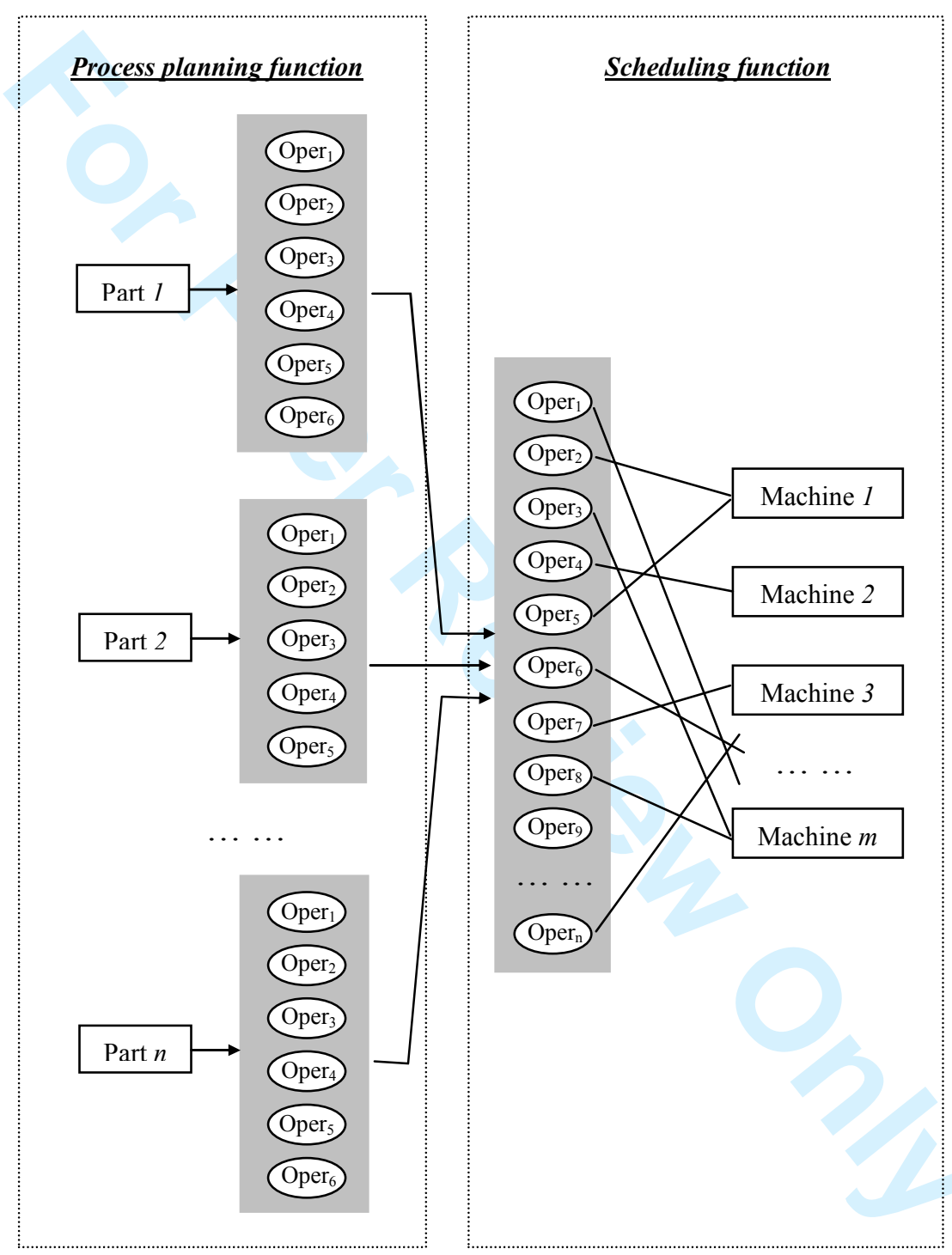

Fig. 4 The interactions of the process planning and scheduling. 
Machines

\begin{tabular}{|c||c||c|}
\hline \multicolumn{2}{|c|}{ Preparation Time } \\
\hline $\begin{array}{c}\text { Set-up } \\
\text { Time }\end{array}$ & $\begin{array}{c}\text { Machine } \\
\text { change Time }\end{array}$ & $\begin{array}{c}\text { Tool change } \\
\text { Time }\end{array}$ \\
\hline
\end{tabular}

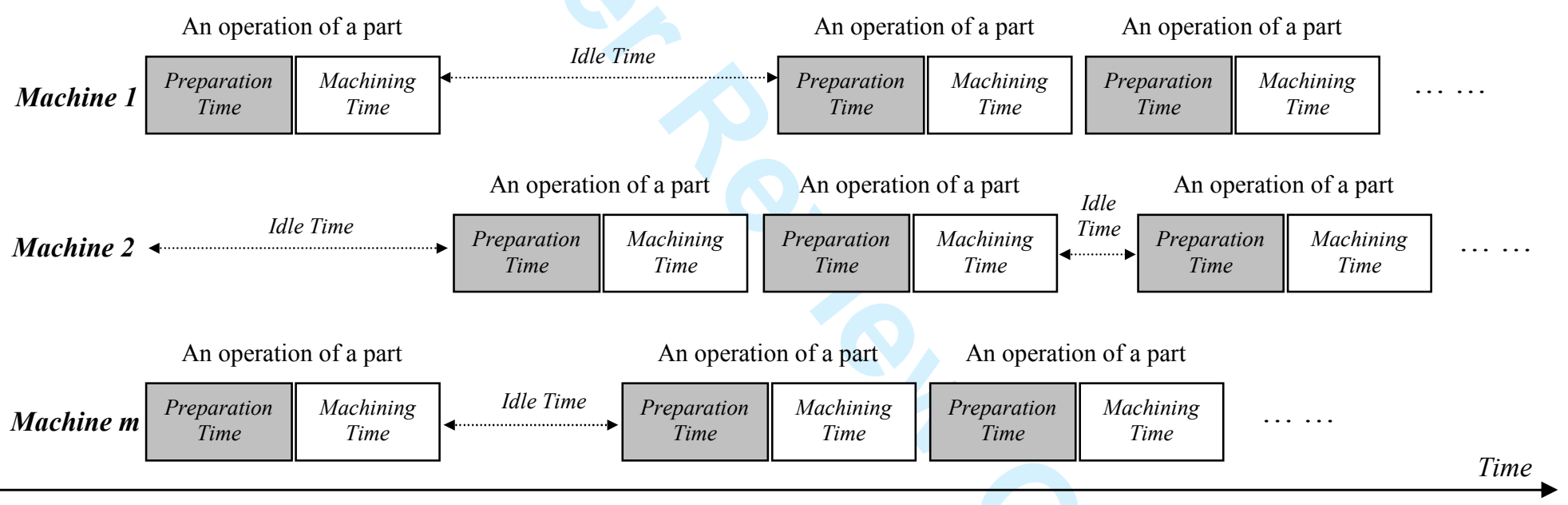

Fig. 5 A Gantt chart for scheduling parts and machining operations. 

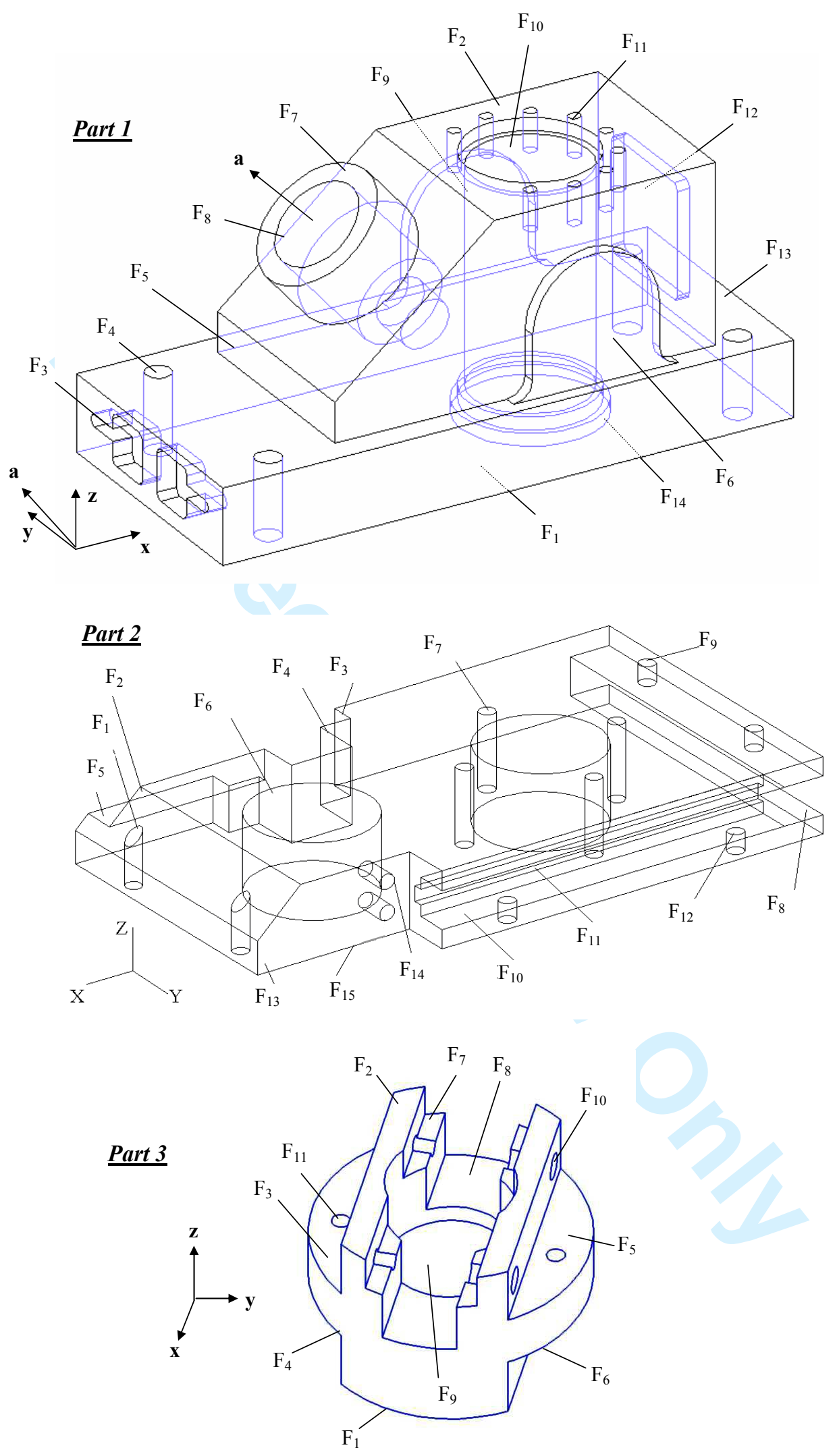

Fig. 6 The three parts in Group 1. 


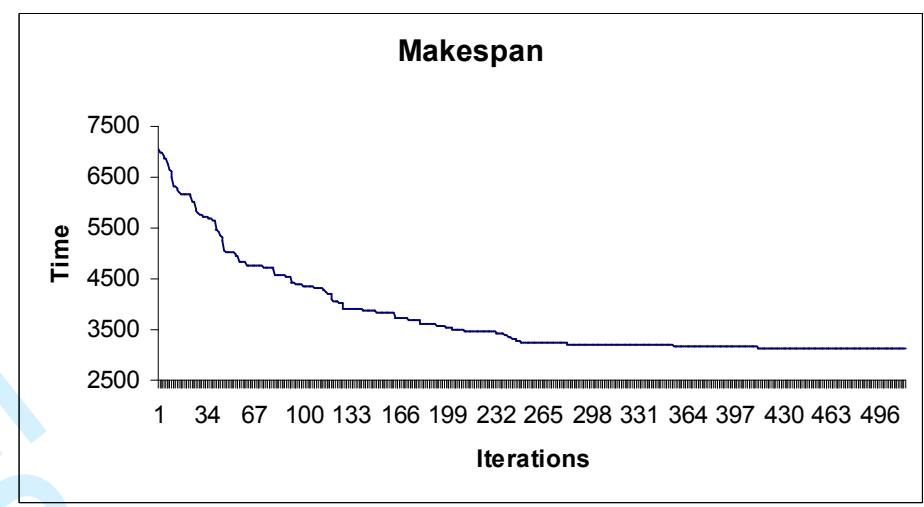

Fig. 7 The optimization results of Condition (1) for the part in Group 1.

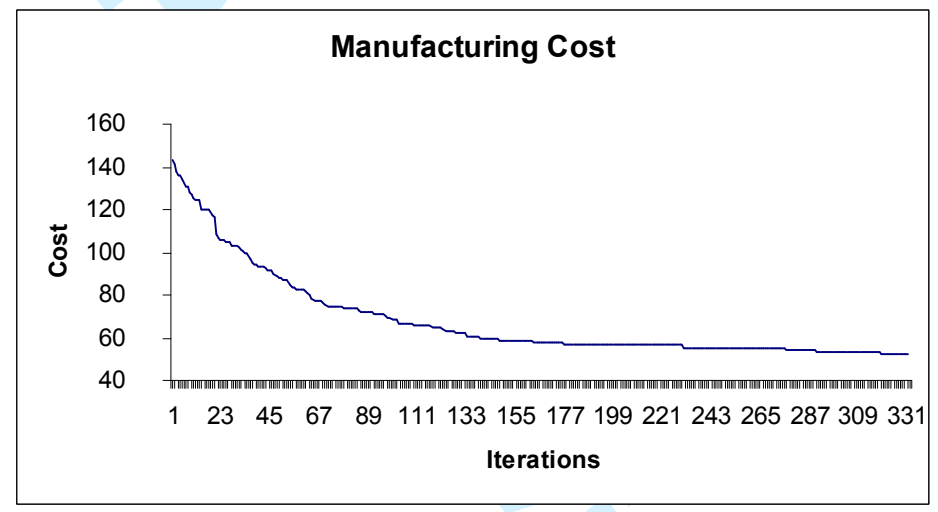

Fig. 8 The optimization results of Condition (2) for the parts in Group 1.

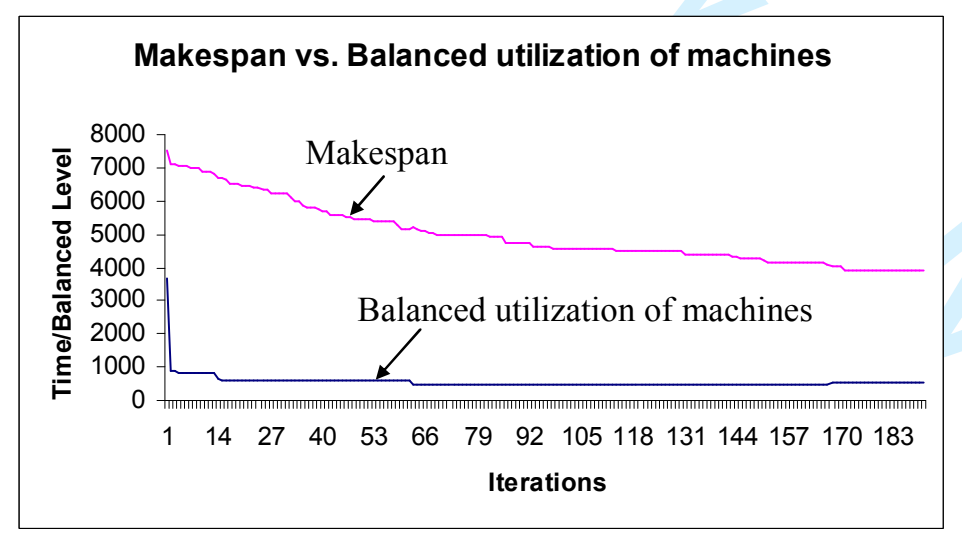

Fig. 9 The optimization results of Condition (3) for the parts in Group 1. 


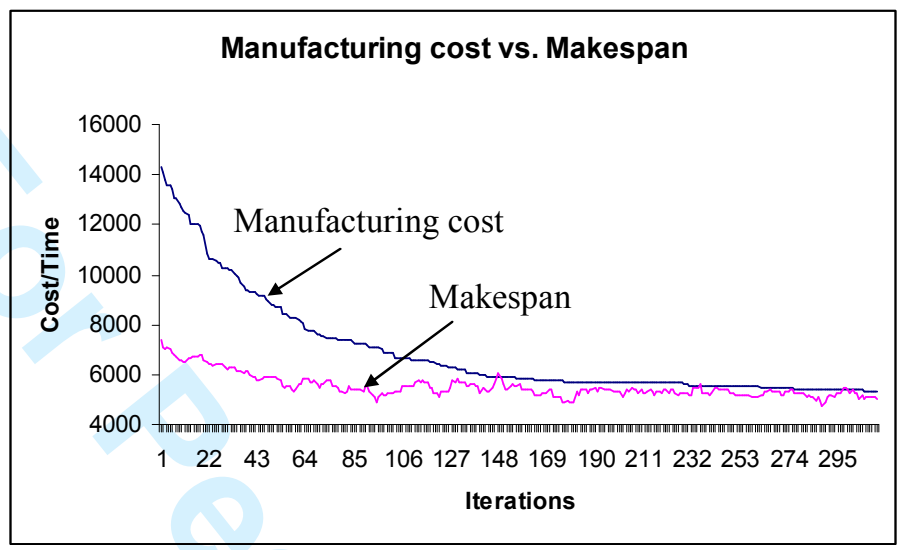

Fig. 10 The comparison of two criteria under the same condition.

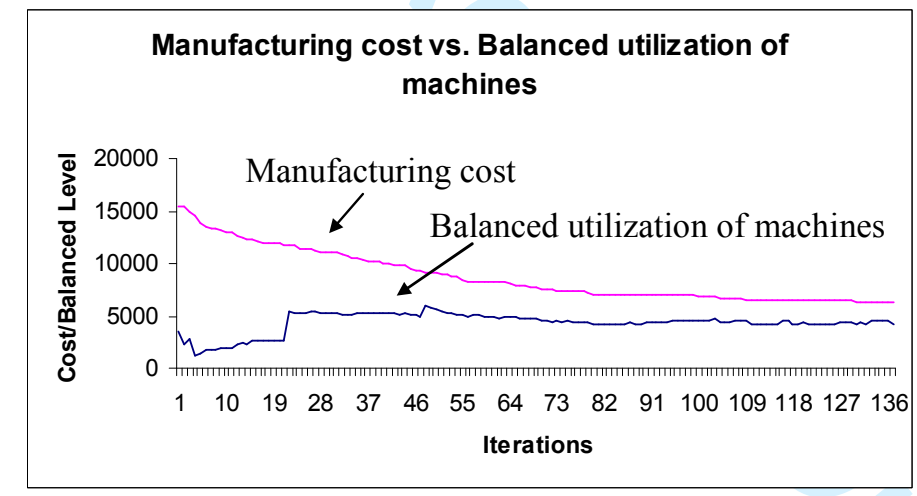

Fig. 11 The comparison of two criteria under the same condition. 


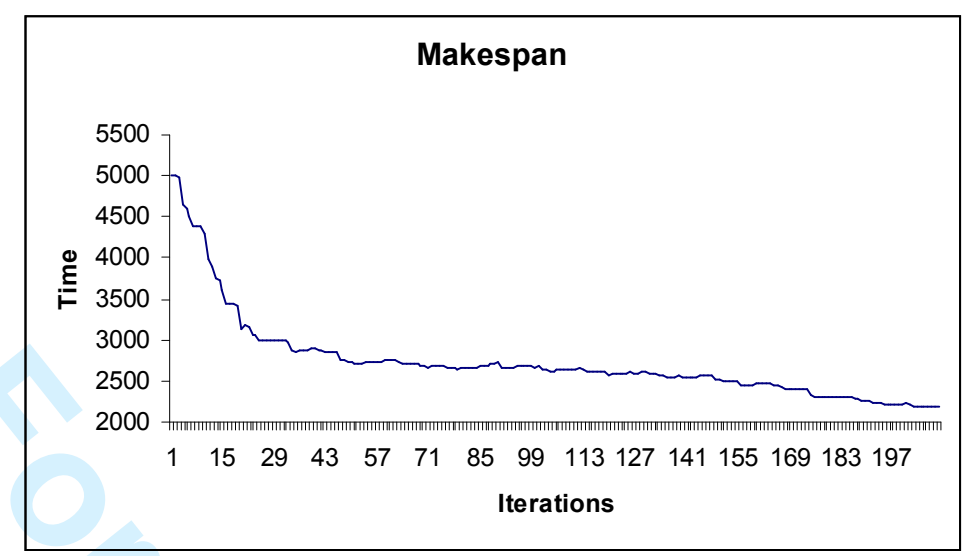

Fig. 12 The optimization results of Condition (1) for the part in Group 2.

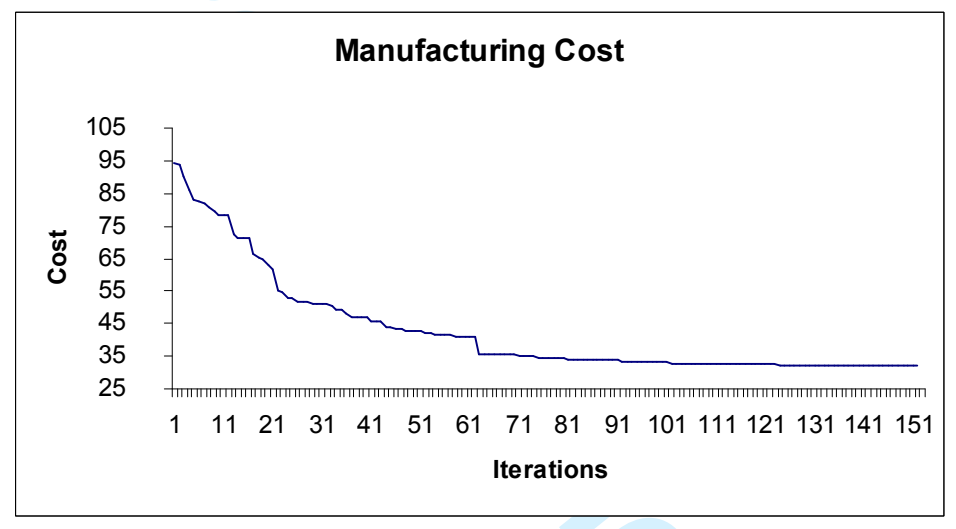

Fig. 13 The optimization results of Condition (2) for the part in Group 2.

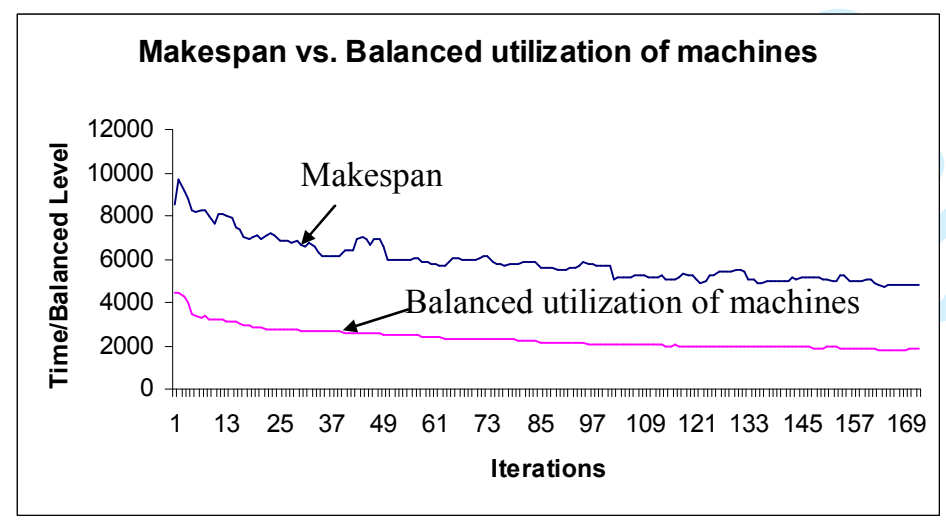

Fig. 14 The optimization results of Condition (3) for the part in Group 2. 


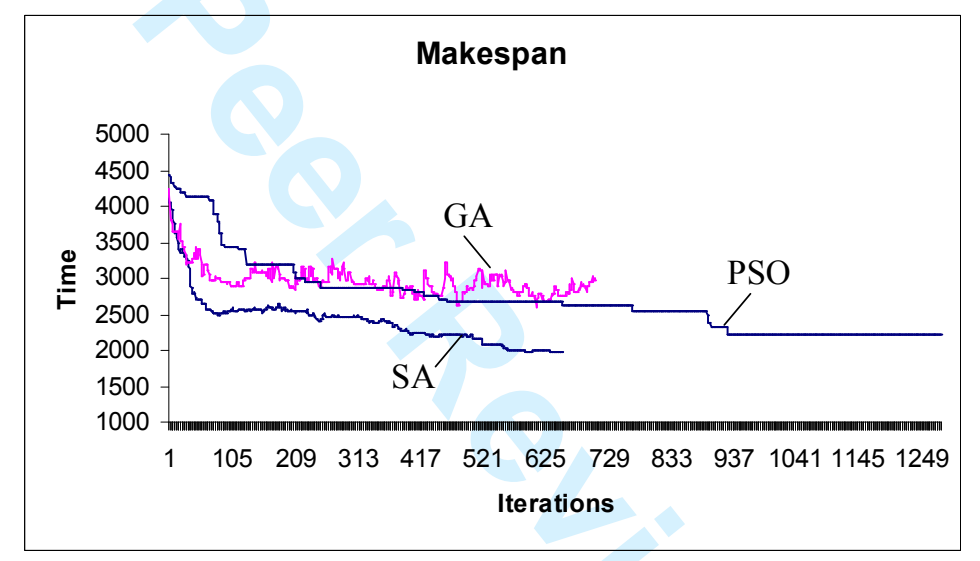

Fig. 15 The comparisons of three approaches for Condition (1) of Group 2. 
Table 1 Definitions of the operation and process plan classes.

\begin{tabular}{|c|c|}
\hline Variables & Descriptions \\
\hline Operation_id & The id of the operation \\
\hline Part_id & The id of the part that the operation belongs to \\
\hline Machine_id & The id of a machine to execute the operation \\
\hline Tool_id & The id of a cutting tool to execute the operation \\
\hline Setup_id & The id of a Set-up (TAD) to apply the operation \\
\hline Machine_list[] & The candidate machine list for executing the operation \\
\hline Tool_list[] & The candidate tool list for executing the operation \\
\hline Setup_list[] & The candidate set-up (TAD) list for applying the operation \\
\hline $\begin{array}{l}\text { Operation_- } \\
\text { parameters }\end{array}$ & Other machining parameters of the operations \\
\hline Setup & The number of the set-up required to execute the operation. It is defined in Equation (1) \\
\hline Setup_T & The setup time, which is defined in Equation (2) \\
\hline$M C$ & $\begin{array}{l}\text { The number of the machine change required to execute the operation, which is defined in } \\
\text { Equation (3) }\end{array}$ \\
\hline$M C_{-} T$ & The machine change time, which is defined in Equation (4) \\
\hline$T C$ & $\begin{array}{l}\text { The number of the tool change required to execute the operation, which is defined in } \\
\text { Equation (5) }\end{array}$ \\
\hline$T C_{-} T$ & The tool change time, which is defined in Equation (6) \\
\hline Pre_T & The preparation time required to execute the operation, which is defined in Equation (7) \\
\hline Idle_T & The idle time before the operation is executed, which is defined in Equation (8) \\
\hline
\end{tabular}

Process_Plan

\begin{tabular}{cl}
\hline Variables & \multicolumn{1}{c}{ Descriptions } \\
\hline Operation $[n]$ & $\begin{array}{l}\text { Define a process plan Proces__Plan based on the above class - Operation. } n \text { is the } \\
\text { number of operations in the plan. }\end{array}$ \\
$T C$ & $\begin{array}{l}\text { Total Cost of the process plan, which includes the set-up cost, the machine change cost, the } \\
\text { tool change cost, the machine utilization cost and the tool utilization cost. }\end{array}$ \\
\hline
\end{tabular}


Table 2 Definitions of a machine class - Machine.

\begin{tabular}{cl}
\hline Variables & \multicolumn{1}{c}{ Descriptions } \\
\hline Machine_id & The id of a machine to execute operations \\
Operation_list [] & The executed operations on this machine \\
Total_T & The total time to use the machine, which is defined in Equation (10) \\
Makespan & The makespan for a group of parts, which is defined in Equation (11) \\
\hline
\end{tabular}


Table 3 The definition of a set-up change.

\begin{tabular}{cc}
\hline Conditions of Machining Two Consecutive Operations & A Set-up Change \\
\hline Same TAD and same part & No \\
Same TAD and different parts & Yes \\
Different TADs and same part & Yes \\
Different TADs and different parts & Yes \\
\hline
\end{tabular}


Table 4 The resource of a job shop - machines and tools.

\begin{tabular}{|c|c|c|}
\hline Types & No. & Cost (\$) \\
\hline Drilling press & $\mathrm{M}_{1}$ & 10 \\
\hline 3-axis vertical milling machine I & $\mathrm{M}_{2}$ & 40 \\
\hline 3 -axis vertical milling machine II & $\mathrm{M}_{3}$ & 40 \\
\hline CNC 3-axis vertical milling machine & $\mathrm{M}_{4}$ & 100 \\
\hline Boring machine & $\mathrm{M}_{5}$ & 60 \\
\hline \multicolumn{3}{|l|}{ Cutting Tools } \\
\hline Types & No. & Cost (\$) \\
\hline Drill 1 & $\mathrm{C}_{1}$ & 7 \\
\hline Drill 2 & $\mathrm{C}_{2}$ & 5 \\
\hline Drill 3 & $\mathrm{C}_{3}$ & 3 \\
\hline Drill 4 & $\mathrm{C}_{4}$ & 8 \\
\hline Tapping tool & $\mathrm{C}_{5}$ & 7 \\
\hline Mill 1 & $\mathrm{C}_{6}$ & 10 \\
\hline Mill 2 & $\mathrm{C}_{7}$ & 15 \\
\hline Mill 3 & $\mathrm{C}_{8}$ & 30 \\
\hline Reaming tool & $\mathrm{C}_{9}$ & 15 \\
\hline Boring tool & $\mathrm{C}_{10}$ & 20 \\
\hline Slot cutter & $\mathrm{C}_{11}$ & 15 \\
\hline Chamfer tool & $\mathrm{C}_{12}$ & 15 \\
\hline
\end{tabular}


Table 5 The technical specifications for Part 1.

\begin{tabular}{|c|c|c|c|c|c|}
\hline Features & Operations & $\begin{array}{c}T A D \\
\text { Candidates }\end{array}$ & $\begin{array}{l}\text { Machine } \\
\text { Candidates }\end{array}$ & $\begin{array}{c}\text { Tool } \\
\text { Candidates }\end{array}$ & $\begin{array}{c}\text { Machining Time for Each } \\
\text { Candidate Machine } \\
\text { (seconds) }\end{array}$ \\
\hline $\mathrm{F}_{1}$ & Milling $\left(\right.$ Oper $\left._{1}\right)$ & $+\mathrm{z}$ & $\mathrm{M}_{2}, \mathrm{M}_{3}, \mathrm{M}_{4}$ & $\mathrm{C}_{6}, \mathrm{C}_{7}, \mathrm{C}_{8}$ & $40,40,30$ \\
\hline $\mathrm{F}_{2}$ & Milling $\left(\right.$ Oper $\left._{2}\right)$ & $-\mathrm{z}$ & $\mathrm{M}_{2}, \mathrm{M}_{3}, \mathrm{M}_{4}$ & $\mathrm{C}_{6}, \mathrm{C}_{7}, \mathrm{C}_{8}$ & $40,40,30$ \\
\hline $\mathrm{F}_{3}$ & Milling $\left(\mathrm{Oper}_{3}\right)$ & $+\mathrm{x}$ & $\mathrm{M}_{2}, \mathrm{M}_{3}, \mathrm{M}_{4}$ & $\mathrm{C}_{6}, \mathrm{C}_{7}, \mathrm{C}_{8}$ & $20,20,15$ \\
\hline $\mathrm{F}_{4}$ & Drilling $\left(\right.$ Oper $\left._{4}\right)$ & $+\mathrm{z},-\mathrm{z}$ & $\mathrm{M}_{1}, \mathrm{M}_{2}, \mathrm{M}_{3}, \mathrm{M}_{4}$ & $\mathrm{C}_{2}$ & $12,10,10,7.5$ \\
\hline $\mathrm{F}_{5}$ & Milling $\left(\mathrm{Oper}_{5}\right)$ & $+\mathrm{x},-\mathrm{z}$ & $\mathrm{M}_{2}, \mathrm{M}_{3}, \mathrm{M}_{4}$ & $\mathrm{C}_{6}, \mathrm{C}_{7}$ & $35,35,26.25$ \\
\hline $\mathrm{F}_{6}$ & Milling $\left(\right.$ Oper $\left._{6}\right)$ & $+\mathrm{y},-\mathrm{z}$ & $\mathrm{M}_{2}, \mathrm{M}_{3}, \mathrm{M}_{4}$ & $\mathrm{C}_{7}, \mathrm{C}_{8}$ & $15,15,11.25$ \\
\hline $\mathrm{F}_{7}$ & Milling $\left(\right.$ Oper $\left._{7}\right)$ & $-\mathrm{a}$ & $\mathrm{M}_{2}, \mathrm{M}_{3}, \mathrm{M}_{4}$ & $\mathrm{C}_{7}, \mathrm{C}_{8}$ & $30,30,22.5$ \\
\hline $\mathrm{F}_{8}$ & $\begin{array}{l}\text { Drilling }\left(\mathrm{Oper}_{8}\right) \\
\text { Reaming }\left(\mathrm{Oper}_{9}\right) \\
\text { Boring }\left(\mathrm{Oper}_{10}\right)\end{array}$ & $-\mathrm{a}$ & $\begin{array}{l}\mathrm{M}_{1}, \mathrm{M}_{2}, \mathrm{M}_{3}, \mathrm{M}_{4} \\
\mathrm{M}_{2}, \mathrm{M}_{3}, \mathrm{M}_{4} \\
\mathrm{M}_{2}, \mathrm{M}_{3}, \mathrm{M}_{4}, \mathrm{M}_{5}\end{array}$ & $\begin{array}{l}\mathrm{C}_{2}, \mathrm{C}_{3}, \mathrm{C}_{4} \\
\mathrm{C}_{9} \\
\mathrm{C}_{10}\end{array}$ & $\begin{array}{l}21.6,18,18,13.5 \\
10,10,7.5 \\
10,10,7.5,12\end{array}$ \\
\hline $\mathrm{F}_{9}$ & Milling (Oper 11$)$ & $-y,-z$ & $\mathrm{M}_{2}, \mathrm{M}_{3}, \mathrm{M}_{4}$ & $\mathrm{C}_{7}, \mathrm{C}_{8}$ & $15,15,11.25$ \\
\hline $\mathrm{F}_{10}$ & $\begin{array}{l}\text { Drilling }\left(\text { Oper }_{12}\right) \\
\text { Reaming }\left(\text { Oper }_{13}\right) \\
\text { Boring }\left(\text { Oper }_{14}\right)\end{array}$ & $-\mathrm{z}$ & $\begin{array}{l}\mathrm{M}_{1}, \mathrm{M}_{2}, \mathrm{M}_{3}, \mathrm{M}_{4} \\
\mathrm{M}_{2}, \mathrm{M}_{3}, \mathrm{M}_{4} \\
\mathrm{M}_{2}, \mathrm{M}_{3}, \mathrm{M}_{4}, \mathrm{M}_{5}\end{array}$ & $\begin{array}{l}\mathrm{C}_{2}, \mathrm{C}_{3}, \mathrm{C}_{4} \\
\mathrm{C}_{9} \\
\mathrm{C}_{10}\end{array}$ & $\begin{array}{l}48,40,40,30 \\
25,25,18.75 \\
25,25,18.75,30\end{array}$ \\
\hline $\mathrm{F}_{11}$ & $\begin{array}{l}\text { Drilling }\left(\text { Oper }_{15}\right) \\
\text { Tapping }\left(\text { Oper }_{16}\right)\end{array}$ & $-\mathrm{z}$ & $\begin{array}{l}\mathrm{M}_{1}, \mathrm{M}_{2}, \mathrm{M}_{3}, \mathrm{M}_{4} \\
\mathrm{M}_{2}, \mathrm{M}_{3}, \mathrm{M}_{4}\end{array}$ & $\begin{array}{l}\mathrm{C}_{1} \\
\mathrm{C}_{5}\end{array}$ & $\begin{array}{l}26.4,22,22,16.5 \\
20,20,15\end{array}$ \\
\hline $\mathrm{F}_{12}$ & Milling (Oper 17$)$ & $-\mathrm{x}$ & $\mathrm{M}_{2}, \mathrm{M}_{3}, \mathrm{M}_{4}$ & $\mathrm{C}_{7}, \mathrm{C}_{8}$ & $16,16,12$ \\
\hline $\mathrm{F}_{13}$ & Milling $\left(\right.$ Oper $\left._{18}\right)$ & $-x,-z$ & $\mathrm{M}_{2}, \mathrm{M}_{3}, \mathrm{M}_{4}$ & $\mathrm{C}_{6}, \mathrm{C}_{7}$ & $35,35,26.25$ \\
\hline $\mathrm{F}_{14}$ & $\begin{array}{l}\text { Reaming }\left(\mathrm{Oper}_{19}\right) \\
\text { Boring }\left(\mathrm{Oper}_{20}\right)\end{array}$ & $+\mathrm{z}$ & $\begin{array}{l}\mathrm{M}_{2}, \mathrm{M}_{3}, \mathrm{M}_{4} \\
\mathrm{M}_{2}, \mathrm{M}_{3}, \mathrm{M}_{4}, \mathrm{M}_{5}\end{array}$ & $\begin{array}{l}\mathrm{C}_{9} \\
\mathrm{C}_{10}\end{array}$ & $\begin{array}{l}12,12,9 \\
12,12,9,14.4\end{array}$ \\
\hline
\end{tabular}

\section{Precedence Constraints}

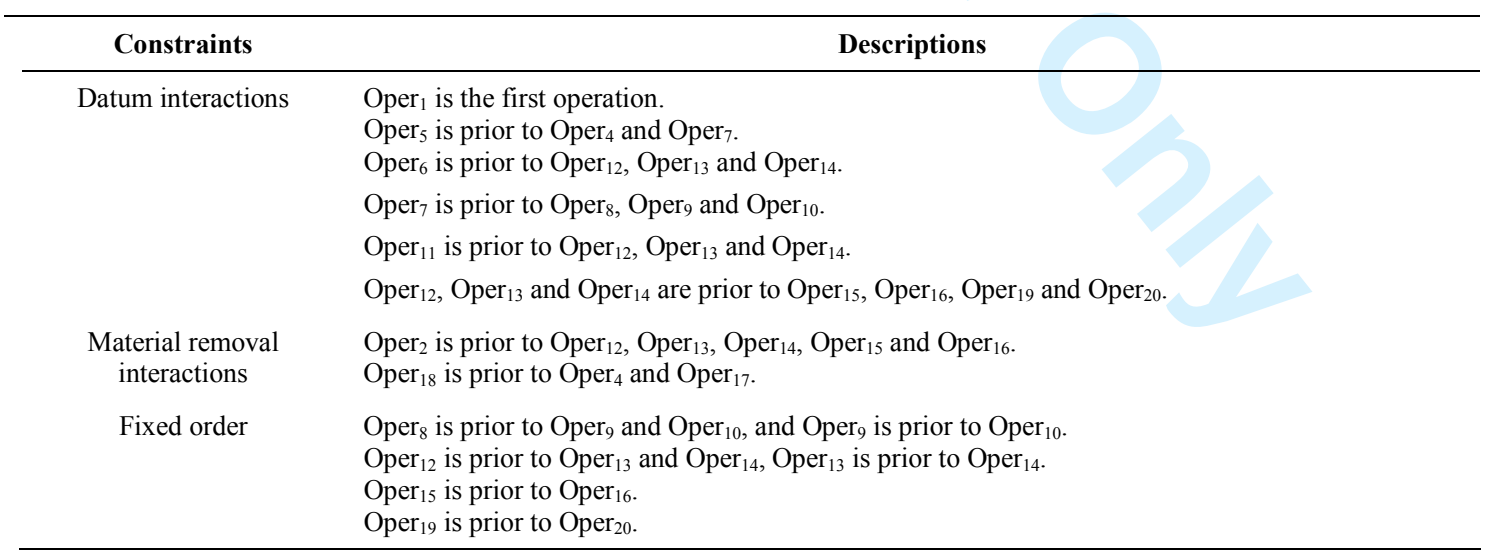


Table 6 The technical specifications for Part 2.

\begin{tabular}{|c|c|c|c|c|c|c|}
\hline Features & \multicolumn{2}{|c|}{ Operations } & $\begin{array}{c}T A D \\
\text { Candidates }\end{array}$ & $\begin{array}{c}\text { Machine } \\
\text { Candidates }\end{array}$ & $\begin{array}{c}\text { Tool } \\
\text { Candidates }\end{array}$ & $\begin{array}{c}\text { Machining Time for } \\
\text { Each Candidate Machine } \\
\text { (seconds) }\end{array}$ \\
\hline $\mathrm{F}_{1}$ & \multicolumn{2}{|c|}{ Drilling $\left(\right.$ Oper $\left._{1}\right)$} & $+\mathrm{z},-\mathrm{z}$ & $\mathrm{M}_{1}, \mathrm{M}_{2}, \mathrm{M}_{3}, \mathrm{M}_{4}$ & $\mathrm{C}_{1}$ & $12,10,10,7.5$ \\
\hline $\mathrm{F}_{2}$ & \multicolumn{2}{|c|}{ Milling $\left(\right.$ Oper $\left._{2}\right)$} & $-\mathrm{x},+\mathrm{y},-\mathrm{y},-\mathrm{z}$ & $\mathrm{M}_{2}, \mathrm{M}_{3}, \mathrm{M}_{4}$ & $\mathrm{C}_{12}$ & $20,20,15$ \\
\hline $\mathrm{F}_{3}$ & \multicolumn{2}{|c|}{ Milling $\left(\mathrm{Oper}_{3}\right)$} & $+\mathrm{y}$ & $\mathrm{M}_{2}, \mathrm{M}_{3}, \mathrm{M}_{4}$ & $\mathrm{C}_{5}, \mathrm{C}_{6}, \mathrm{C}_{11}$ & $18,18,13.5$ \\
\hline $\mathrm{F}_{4}$ & \multicolumn{2}{|c|}{ Milling $\left(\mathrm{Oper}_{4}\right)$} & $+\mathrm{y}$ & $\mathrm{M}_{2}, \mathrm{M}_{3}, \mathrm{M}_{4}$ & $\mathrm{C}_{6}, \mathrm{C}_{7}, \mathrm{C}_{8}$ & $16,16,12$ \\
\hline $\mathrm{F}_{5}$ & \multicolumn{2}{|c|}{ Milling (Oper 5 ) } & $+\mathrm{y},-\mathrm{z}$ & $\mathrm{M}_{2}, \mathrm{M}_{3}, \mathrm{M}_{4}$ & $\mathrm{C}_{6}, \mathrm{C}_{7}, \mathrm{C}_{8}$ & $15,15,11.25$ \\
\hline \multirow[t]{2}{*}{$\mathrm{F}_{6}$} & \multicolumn{2}{|c|}{ Drilling $\left(\mathrm{Oper}_{6}\right)$} & $+\mathrm{z},-\mathrm{z}$ & $\mathrm{M}_{1}, \mathrm{M}_{2}, \mathrm{M}_{3}, \mathrm{M}_{4}$ & $\mathrm{C}_{2}$ & $30,25,25,18.75$ \\
\hline & \multicolumn{2}{|c|}{ Reaming $\left(\mathrm{Oper}_{7}\right)$} & $+\mathrm{z},-\mathrm{z}$ & $\mathrm{M}_{2}, \mathrm{M}_{3}, \mathrm{M}_{4}$ & $\mathrm{C}_{9}$ & $25,25,18.75$ \\
\hline $\mathrm{F}_{7}$ & \multicolumn{2}{|c|}{ Drilling $\left(\right.$ Oper $\left._{8}\right)$} & $+\mathrm{z},-\mathrm{z}$ & $\mathrm{M}_{1}, \mathrm{M}_{2}, \mathrm{M}_{3}, \mathrm{M}_{4}$ & $\mathrm{C}_{1}$ & $14.4,12,12,9$ \\
\hline $\mathrm{F}_{8}$ & \multicolumn{2}{|c|}{ Milling (Oper 9 ) } & $+\mathrm{x}$ & $\mathrm{M}_{2}, \mathrm{M}_{3}, \mathrm{M}_{4}$ & $\mathrm{C}_{6}, \mathrm{C}_{7}, \mathrm{C}_{8}$ & $15,15,11.25$ \\
\hline $\mathrm{F}_{9}$ & \multicolumn{2}{|c|}{ Drilling $\left(\right.$ Oper $\left._{10}\right)$} & $-\mathrm{z}$ & $\mathrm{M}_{1}, \mathrm{M}_{2}, \mathrm{M}_{3}, \mathrm{M}_{4}$ & $\mathrm{C}_{1}$ & $9.6,8,8,6$ \\
\hline $\mathrm{F}_{10}$ & \multicolumn{2}{|c|}{ Milling (Oper 11$)$} & $-\mathrm{y}$ & $\mathrm{M}_{2}, \mathrm{M}_{3}, \mathrm{M}_{4}$ & $\mathrm{C}_{6}, \mathrm{C}_{7}, \mathrm{C}_{8}$ & $10,10,7.5$ \\
\hline $\mathrm{F}_{11}$ & \multicolumn{2}{|c|}{ Milling $\left(\right.$ Oper $\left._{12}\right)$} & $-\mathrm{y}$ & $\mathrm{M}_{2}, \mathrm{M}_{3}, \mathrm{M}_{4}$ & $\mathrm{C}_{6}, \mathrm{C}_{7}, \mathrm{C}_{8}$ & $10,10,7.5$ \\
\hline $\mathrm{F}_{12}$ & \multicolumn{2}{|c|}{ Drilling $\left(\right.$ Oper $\left._{13}\right)$} & $+\mathrm{z},-\mathrm{z}$ & $\mathrm{M}_{1}, \mathrm{M}_{2}, \mathrm{M}_{3}, \mathrm{M}_{4}$ & $\mathrm{C}_{1}$ & $9.6,8,8,6$ \\
\hline $\mathrm{F}_{13}$ & \multicolumn{2}{|c|}{ Milling (Oper 14$)$} & $-\mathrm{x},-\mathrm{y}$ & $\mathrm{M}_{2}, \mathrm{M}_{3}, \mathrm{M}_{4}$ & $\mathrm{C}_{6}, \mathrm{C}_{7}, \mathrm{C}_{8}$ & $16,16,12$ \\
\hline $\mathrm{F}_{14}$ & \multicolumn{2}{|c|}{ Drilling (Oper $\left.{ }_{15}\right)$} & $-\mathrm{y}$ & $\mathrm{M}_{1}, \mathrm{M}_{2}, \mathrm{M}_{3}, \mathrm{M}_{4}$ & $\mathrm{C}_{1}$ & $9.6,8,8,6$ \\
\hline $\mathrm{F}_{15}$ & \multicolumn{2}{|c|}{$\operatorname{Milling}\left(\operatorname{Oper}_{16}\right)$} & $\begin{array}{l}+\mathrm{x},-\mathrm{x},+\mathrm{y},- \\
\mathrm{y},+\mathrm{z}\end{array}$ & $\mathrm{M}_{1}, \mathrm{M}_{2}, \mathrm{M}_{3}, \mathrm{M}_{4}$ & $\mathrm{C}_{6}, \mathrm{C}_{7}, \mathrm{C}_{8}$ & $36,30,30,22.5$ \\
\hline \multicolumn{7}{|c|}{ Precedence Constraints } \\
\hline \multicolumn{3}{|c|}{ Constraints } & \multirow{2}{*}{\multicolumn{3}{|c|}{ Descriptions }} & \\
\hline Tool i & nteractions & Ope & & & & \\
\hline \multicolumn{2}{|c|}{ Datum interactions } & \multicolumn{3}{|c|}{$\begin{array}{l}\text { Oper }_{6} \text { and Oper } \\
\text { Ophould be prior to Oper } \\
\text { Oper }_{11} \text { should be prior to Oper } \\
\text { Oper }_{14} \text { should be prior to Oper } \\
\text { s. }\end{array}$} & & \\
\hline \multicolumn{2}{|c|}{ Thin-wall interactions } & \multicolumn{3}{|c|}{$\begin{array}{l}\text { Oper, should be prior to Oper } 8 \\
\text { Oper }_{12} \text { should be prior to } \text { Oper }_{10} \text {. }\end{array}$} & & \\
\hline \multicolumn{2}{|c|}{$\begin{array}{l}\text { Material removal } \\
\text { interactions }\end{array}$} & \multicolumn{3}{|c|}{$\begin{array}{l}\text { Oper } \text { should be prior to Oper }_{10} \text {. } \\
\text { Oper }_{11} \text { should be prior to Oper }_{13} \text {. } \\
\text { Oper }_{14} \text { should be prior to } \text { Oper }_{15} \text {. } \\
\text { Oper }_{3} \text { should be prior to Oper }_{4} \text {. }\end{array}$} & & \\
\hline \multicolumn{2}{|c|}{ Fixed order } & \multicolumn{3}{|c|}{ Oper $_{6}$ should be prior to Oper $_{7}$} & & \\
\hline
\end{tabular}


Table 7 The technical specifications for Part 3.

\begin{tabular}{|c|c|c|c|c|c|}
\hline Features & Operations & $\begin{array}{c}\text { TAD } \\
\text { Candidates }\end{array}$ & $\begin{array}{l}\text { Machine } \\
\text { Candidates }\end{array}$ & $\begin{array}{c}\text { Tool } \\
\text { Candidates }\end{array}$ & $\begin{array}{c}\text { Machining Time for Each } \\
\text { Candidate Machine } \\
\text { (seconds) }\end{array}$ \\
\hline $\mathrm{F}_{1}$ & Milling (Oper $\left.{ }_{1}\right)$ & $+\mathrm{z}$ & $\mathrm{M}_{2}, \mathrm{M}_{3}, \mathrm{M}_{4}$ & $\mathrm{C}_{6}, \mathrm{C}_{7}, \mathrm{C}_{8}$ & $20,20,15$ \\
\hline $\mathrm{F}_{2}$ & Milling $\left(\mathrm{Oper}_{2}\right)$ & $-\mathrm{z}$ & $\mathrm{M}_{2}, \mathrm{M}_{3}, \mathrm{M}_{4}$ & $\mathrm{C}_{6}, \mathrm{C}_{7}, \mathrm{C}_{8}$ & $20,20,15$ \\
\hline $\mathrm{F}_{3}$ & Milling $\left(\mathrm{Oper}_{3}\right)$ & $+\mathrm{x},-\mathrm{x},+\mathrm{y},-\mathrm{z}$ & $\mathrm{M}_{2}, \mathrm{M}_{3}, \mathrm{M}_{4}$ & $\mathrm{C}_{6}, \mathrm{C}_{7}, \mathrm{C}_{8}$ & $15,15,11.25$ \\
\hline $\mathrm{F}_{4}$ & Milling $\left(\mathrm{Oper}_{4}\right)$ & $+\mathrm{x},-\mathrm{x},+\mathrm{y},+\mathrm{z}$ & $\mathrm{M}_{1}, \mathrm{M}_{2}, \mathrm{M}_{3}, \mathrm{M}_{4}$ & $\mathrm{C}_{2}$ & $15,15,11.25,18$ \\
\hline $\mathrm{F}_{5}$ & Milling (Oper $\left.{ }_{5}\right)$ & $+\mathrm{x},-\mathrm{x},-\mathrm{y},-\mathrm{z}$ & $\mathrm{M}_{2}, \mathrm{M}_{3}, \mathrm{M}_{4}$ & $\mathrm{C}_{6}, \mathrm{C}_{7}, \mathrm{C}_{8}$ & $15,15,11.25$ \\
\hline $\mathrm{F}_{6}$ & Milling $\left(\mathrm{Oper}_{6}\right)$ & $+\mathrm{x},-\mathrm{x},-\mathrm{y},+\mathrm{z}$ & $\mathrm{M}_{2}, \mathrm{M}_{3}, \mathrm{M}_{4}$ & $\mathrm{C}_{7}, \mathrm{C}_{8}$ & $15,15,11.25$ \\
\hline $\mathrm{F}_{7}$ & Milling $\left(\mathrm{Oper}_{7}\right)$ & $+\mathrm{x},-\mathrm{x},-\mathrm{z}$ & $\mathrm{M}_{2}, \mathrm{M}_{3}, \mathrm{M}_{4}$ & $\mathrm{C}_{7}, \mathrm{C}_{8}, \mathrm{C}_{11}$ & $15,15,11.25$ \\
\hline $\mathrm{F}_{8}$ & Milling $\left(\mathrm{Oper}_{8}\right)$ & $+\mathrm{x},-\mathrm{x},-\mathrm{z}$ & $\mathrm{M}_{2}, \mathrm{M}_{3}, \mathrm{M}_{4}$ & $\begin{array}{l}\mathrm{C}_{6}, \mathrm{C}_{7}, \mathrm{C}_{8} \\
\mathrm{C}_{11}\end{array}$ & $25,25,18.75$ \\
\hline $\mathrm{F}_{9}$ & $\begin{array}{l}\text { Drilling }\left(\mathrm{Oper}_{9}\right) \\
\text { Reaming }\left(\mathrm{Oper}_{10}\right) \\
\text { Boring }\left(\mathrm{Oper}_{11}\right)\end{array}$ & $+\mathrm{z},-\mathrm{z}$ & $\begin{array}{l}\mathrm{M}_{1}, \mathrm{M}_{2}, \mathrm{M}_{3}, \mathrm{M}_{4} \\
\mathrm{M}_{2}, \mathrm{M}_{3}, \mathrm{M}_{4} \\
\mathrm{M}_{2}, \mathrm{M}_{3}, \mathrm{M}_{4}, \mathrm{M}_{5}\end{array}$ & $\begin{array}{l}\mathrm{C}_{2}, \mathrm{C}_{3}, \mathrm{C}_{4} \\
\mathrm{C}_{9} \\
\mathrm{C}_{10}\end{array}$ & $\begin{array}{l}30,25,25,18.75 \\
20,20,15 \\
20,20,15,24\end{array}$ \\
\hline $\mathrm{F}_{10}$ & $\begin{array}{l}\text { Drilling }\left(\text { Oper }_{12}\right) \\
\text { Tapping }\left(\text { Oper }_{13}\right)\end{array}$ & $+\mathrm{y},-\mathrm{y}$ & $\begin{array}{l}\mathrm{M}_{1}, \mathrm{M}_{2}, \mathrm{M}_{3}, \mathrm{M}_{4} \\
\mathrm{M}_{2}, \mathrm{M}_{3}, \mathrm{M}_{4}\end{array}$ & $\begin{array}{l}\mathrm{C}_{1} \\
\mathrm{C}_{5}\end{array}$ & $\begin{array}{l}9.6,8,8,6 \\
8,8,6\end{array}$ \\
\hline $\mathrm{F}_{11}$ & Drilling $\left(\right.$ Oper $\left._{14}\right)$ & $+\mathrm{z},-\mathrm{z}$ & $\mathrm{M}_{1}, \mathrm{M}_{2}, \mathrm{M}_{3}, \mathrm{M}_{4}$ & $\mathrm{C}_{9}$ & $6,5,5,3.75$ \\
\hline \multicolumn{6}{|c|}{ Precedence Constraints } \\
\hline & Constraints & \multicolumn{4}{|c|}{ Descriptions } \\
\hline \multicolumn{2}{|c|}{ Datum interactions } & \multicolumn{4}{|c|}{ 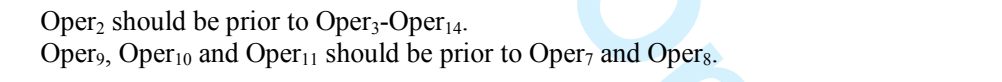 } \\
\hline \multicolumn{2}{|c|}{ Material removal interactions } & \multicolumn{3}{|c|}{ 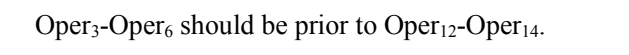 } & \\
\hline \multicolumn{2}{|r|}{ Fixed order } & \multicolumn{3}{|c|}{ Oper $_{9}-$ Oper $_{10}-$ Oper $_{11}$} & \\
\hline
\end{tabular}


Table 8 The technical specifications for the part in Group 2.

\begin{tabular}{clc}
\hline Parts & $\begin{array}{c}\text { Numbers of Operations (with Numbers of Alternative } \\
\text { Machining Plans for Each Operation) }\end{array}$ & \begin{tabular}{c} 
Numbers of Constraints \\
\hline 1
\end{tabular} \\
\hline 2 & $8(9,9,27,8,8,9,36)$ & 11 \\
3 & $7(9,9,36,18,27,8,27,18)$ & 11 \\
4 & $9(9,9,27,6,36,18,6,6)$ & 10 \\
5 & $7(9,9,36,36,36,18,6)$ & 18 \\
6 & $9(9,9,36,27,18,6,27,6,18)$ & 13 \\
7 & $5(9,27,27,18,9)$ & 20 \\
8 & $7(9,9,27,36,36,6,6)$ & 5 \\
\hline
\end{tabular}

